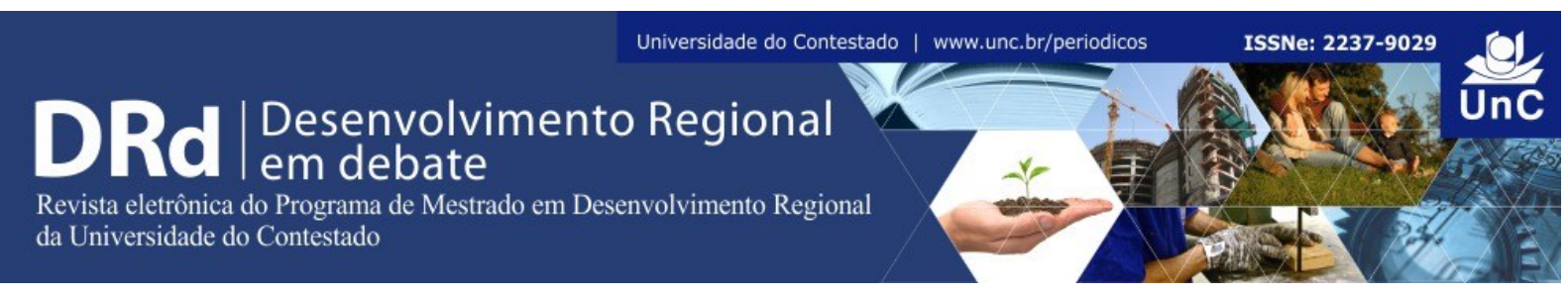

\title{
LAS RELACIONES DE LAS ESTRATEGIAS EN EL RESULTADO EXPORTADOR EN PEQUEÑAS Y MEDIANAS EMPRESAS
}

\author{
Marina Guarrochena de Arjol $^{1}$ \\ Juan Antonio Dip ${ }^{2}$
}

\begin{abstract}
RESUMEN
El propósito principal del artículo identifica los rasgos diferenciales de las estrategias competitivas para lograr superiores resultados de exportación, en Pequeñas y Medianas Empresas de la industria de la madera de Misiones, Argentina; mediante el examen de las relaciones de las estrategias en los resultados de exportación. El estudio se basa en un enfoque sistémico y holística para analizar, empíricamente, la inter relación de las características de la organización, el compromiso de exportación, el entorno, y los tipos de estrategias implementadas, que influyen, directa e indirectamente, sobre el resultado exportador. Se evalúan los tipos de estrategias competitivas con orientación al mercado externo, de acuerdo a la tipología de Miles y Snow (1978). En una muestra de empresas, se identifica el perfil estratégico de las empresas por el método de indicadores objetivos. En un análisis descriptivo y correlacional, se observan las posibles relaciones existentes entre las variables planteadas, aplicando un modelo regresión múltiple. Los mejores resultados están relacionados con la innovación en productos de mayor valor agregado, la intensidad de la exportación, la presencia en ferias comerciales y el grado de percepción del impacto de las barreras en el mercado nacional e internacional, que condicionan su forma de reaccionar frente a los cambios del entorno. Muestra el importante papel de la innovación de productos de mayor valor agregado y actividades de promoción y vinculación en las estrategias exploradoras, que aumentarían el desarrollo proactivo de los comportamientos estratégicos, haciendo una contribución positiva a los resultados de exportación.
\end{abstract}

Palabras Clave: Resultado de la exportación. Estrategias. Perfiles estratégicos. Pequeñas y Medianas empresas. Madera y sus manufacturas.

\footnotetext{
${ }^{1}$ Magister en Administración Estratégica, UNaM- Argentina y en Integración Económica, UIA- España; Profesora e Investigadora, Facultad de Ciencias Económicas, UNaM; con actuación en la Maestría en Desarrollo Regional e Integración, UGD; Posadas, Misiones, Argentina. Correo electrónico: mgarjol@gmail.com.

2 Licenciado en Economía. Universidad Nacional de Tucumán y Doctorando en Economía, UCA-Argentina. Profesor e Investigador, Facultad de Ciencias Económicas, UNaM; con actuación en la Maestría en Desarrollo Regional e Integración, UGD; Posadas, Misiones, Argentina. Correo electrónico: dip @,fce.unam.edu.ar.
} 


\title{
THE RELATIONSHIPS STRATEGIES ON EXPORT PERFORMANCE IN SMALL AND MEDIUM ENTERPRISES
}

\begin{abstract}
The main purpose of the article identifies the different traits of the competitive strategies, to achieve superior export performance, in small and medium-sized enterprises of the industry of wood in Misiones, Argentina; through the examination of the relations of the strategies on export performance. The study is based on a systemic and holistic approach, to analyze, empirically, the inter relationship of the characteristics of the organization, committed to export, the environment, and the types of strategies implemented, influencing, directly and indirectly, on the export result. The types of competitive strategies oriented to foreign market, according to the typology of Miles and Snow (1978) are evaluated. In a sample of companies, the strategic profile of the companies is identified by the method of objective indicators. In a descriptive and correlational analysis, the possible existing relations are observed between the variables raised, applying a multiple regression model. The best results are related to the innovation in products of major added value, the intensity of the exportation, the presence in trade fairs and the degree of perception of the impact of the national and international market barriers affecting the way they react to changes in the environment. It shows the important role of the innovation of products of major added value and promotional activities and linking in the prospectors strategies, which would increase the proactive development of the strategic behaviors, making a positive contribution to the export performance.
\end{abstract}

Keywords: Export performance. Strategies. Strategic profiles. Small and Medium enterprises. Manufactured wood products.

\section{INTRODUCCIÓN}

La estrategia competitiva a nivel de negocio, se ha convertido en un tema importante en el campo de la gestión estratégica. Es un proceso dinámico, interactivo y complejo, que se compone de una serie de decisiones y acciones de la empresa afectados por factores internos y externos relacionados entre sí, con el fin de alcanzar los objetivos estratégicos.

Asimismo, las empresas eligen deliberadamente la estrategia apropiada para ajustarse a la especificidad de su entorno, dependiendo de factores internos de la organización como las capacidades y recursos, y externos como la evolución de la economía, oscilaciones de la demanda y posición de la competencia (GARCÍA PEREZ DE LEMA; GALLEGO, 2006, p. 437).

La relación entre las estrategias implementadas y los resultados de la exportación puede ser diferente según sea la estrategia de negocio seguida por la empresa y puede comportarse de manera diferente en diferentes contextos. Al respecto, Flor Peris y Oltra Mestre (2010) señalan que pocos autores han analizado combinaciones de las diferentes dimensiones de la estrategia exportadora y su influencia conjunta sobre el desempeño exportador, que revelan la importancia, "[...] de las tipologías y las taxonomías para 
identificar patrones estratégicos en diferentes contextos" (FLOR PERIS; OLTRA MESTRE, 2010, p.19).

Miles y Snow (1978) desarrollan el perfil estratégico basados en el ciclo de adaptación de las empresas y consiste en clasificar en cuatro tipos de estrategias: exploradora, analizadora, defensora y reactiva. Estos autores se basan en las "[...] formas alternativas en que la organización define sus dominios producto-mercado (estrategia) y la construcción de mecanismos (estructuras y procesos) para perseguir estas estrategias" (MILES et al., 2003, p. 546).

Esta tipología ha sido ampliamente utilizada y reconocida su aplicabilidad en el contexto de las PyMes (RAYMOND; BERGERON, 2008; ARAGÓN SÁNCHEZ; SÁNCHEZ, 2005; GIMENEZ, 1999).

A pesar que las exportaciones de productos de madera y manufacturas de la provincia de Misiones, Argentina, representan el $40 \%$ de las ventas externas totales de Argentina, el protagonismo de las Pequeñas y Medianas Empresas -PyMes- es escaso. Su participación en el valor en las exportaciones es del $15 \%$, en los últimos 5 años, con debilidades de la estructura exportadora y baja continuidad exportadora. Sin embargo, las PyMes tienen una canasta exportadora diversificada en productos y compite en mercados exigentes de calidad en el mercado de la madera (GUARROCHENA et al., 2013).

En este contexto, resulta relevante analizar los rasgos diferenciales de las estrategias competitivas de PyMes orientadas a la actividad de exportación de madera y sus manufacturas, en la provincia de Misiones, de manera de contribuir al mejoramiento de su desempeño de las exportaciones.

Esta investigación examina la asociación del resultado exportador con las interrelaciones de las características de la organización, el compromiso de exportación, el entorno, y los tipos de estrategias implementadas en el marco de la tipología de Miles y Snow (1978), que permiten a la empresa alcanzar mejores resultados.

\section{MARCO TEÓRICO}

Diversos estudios en la gestión estratégica y de negocios internacionales identifican las estrategias competitivas como uno de los factores determinantes del resultado exportador.

En general, la revisión de la literatura indica varios factores que influyen en los resultados de exportación en relación con el ambiente externo, las características organizativas y de gestión y la estrategia específica adoptada de exportación (CARNEIRO; DA ROCHA; DA SILVA, 2011, p. 113).

Según Lages y Sousa (2010) los estudios realizados de las relaciones entre las fuerzas internas y externas, la estrategia de exportación y el desempeño o comportamiento exportador, demuestran "[...] que los resultados de exportación debe ser analizada en función 
de la adecuación entre el medio ambiente de la empresa y el estrategia de exportación seleccionada" (LAGES; SOUSA, 2010, p. 4).

El modelo analítico de factores que influyen el éxito exportador de Milesi, Yoguel y Moori (2002) se refieren sustancialmente a las capacidades competitivas de la empresa (tecnológicos y organizacionales), las oportunidades del negocio y el clima del entorno; a partir de procesos de aprendizaje que sustentan la inserción externa de las empresas (MILESI; YOGUEL; MOORI, 2002, p. 93-97).

Alonso y Donoso (1998) consideran a las estrategias competitivas de la actividad exportadora, como resultado de un sistema dinámico de factores internos y externos dado que están sujetos a un proceso continuo de cambio, que van generando transformaciones y acumulación de capacidades y experiencias por parte de la empresa. Y ante esto señala que "[...] el pasado explica buena parte de sus capacidades acumuladas y condiciona el marco de sus posibles opciones futuras" (ALONSO; DONOSO, 1998, 83-87).

Una perspectiva de adaptación de la relación entre la organización y el entorno presupone, según Frishammar (2006), que las organizaciones activas se adaptan a los cambios dentro su entorno a través de la toma y aplicación de decisiones que alteran su estrategia, la estructura y los procesos (FRISHAMMAR, 2006, p.37).

Por lo que, la estrategia resultaría de la reacción de los resultados anteriores, en la relación existente entre la orientación de mercado y su rendimiento, con el entorno del mercado.

Miles y Snow (1978) desarrollaron una tipología de estrategias genéricas, a nivel de negocio de una empresa, sobre un modelo teórico en función del proceso de adaptación de las organizaciones en la interacción con el entorno y consecuentemente las estrategias que adoptan. Argumentaron que las diferentes estrategias de la empresa se deben a la forma en que las empresas deciden hacer frente y resuelven tres problemas fundamentales: empresarial, en cómo abordar la gestión estratégica de los productos-mercados; ingeniería u operativos de los sistemas de producción y distribución de productos; y problemas administrativos en el desarrollo de la estructura organizativa y los procesos de apoyo a las decisiones empresariales y de ingeniería.

Las tipologías estratégicas de las organizaciones se clasificaron en:

a) Exploradoras: están casi siempre atentos a la aparición de oportunidades de mercado. Regularmente experimentan con respuestas para las tendencias emergentes del entorno. Están muy involucrados en innovaciones de productos y mercados.

b) Defensoras: operan en un entorno estable y estrecho en la definición de productomercado. Están orientados internamente y enfatizan la reducción de costes. La estrategia de defensa implica una decisión de no perseguir agresivamente nuevos mercados sino conducir hacia a mercados estables, y obtener incrementos de eficiencia en sus operaciones.

c) Analizadoras: comparten características de las estrategias anteriores y buscan un equilibrio entre dominios estables y cambiantes, al mismo tiempo, sigue una 
estrategia de minimización de riesgos y de búsqueda de nuevas oportunidades. En entornos estables operan de forma rutinaria, formal y eficiente, y en entornos turbulentos son seguidores de los competidores más innovadores.

d) Reactoras o reactivas: No responden de forma efectiva a los cambios del entorno. Inconsistencia en la adaptación de sus estructuras a las estrategias cuyo ajuste es normalmente forzado por la presión del entorno (MILES et al, 2003, p. 548- 558).

Estos autores señalan que las empresas defensoras, analizadoras y exploradoras son formas estables de organización, a saber, si hay una alineación entre la estrategia elegida y la estructura organizativa y los procesos, que cualquiera de estas estrategias pueden conducir a la organización a ser un competidor efectivo en una industria en particular.

En la caracterización de formas inestables de organización, denominados reactoresreactivas, existe una falta de alineación entre la estrategia y la estructura, y dará lugar a la firma de ser un competidor ineficaz en la industria. Sin embargo, estudios contemporáneos sobre este tipo de estrategia, señalan la ambigüedad de su definición operativa y existen escasos argumentos que indiquen la necesidad de incluirlas (GARCÍA PEREZ DE LEMA; GALLEGO, 2006; CABELLO MEDINA et al., 2000).

En este trabajo se han considerado un conjunto de diversos factores microorganizacionales, determinantes del comportamiento de las exportaciones y las estrategias implementadas, a través del perfil estratégico, que influyen en el resultado exportador de las empresas y dependen del contexto específico de las empresas en estudio.

\section{RESULTADOS DE EXPORTACIÓN}

El resultado de exportación es la extensión de los objetivos económicos como estratégicos de la empresa, logrados a través la gestión estratégica en las operaciones de la exportación y ejecución de la estrategia de comercialización internacional (NAVARRO et al., 2010; CAVUSGIL; ZOU, 1994).

La naturaleza multi dimensional del resultado exportador hace que sea difícil de comparar y contrastar las conclusiones de diferentes estudios, pero no existe uniformidad en cuanto a los tipos de indicadores utilizados para medir el resultado exportador. Las medidas más utilizadas son: intensidad, ventas, cuota de mercado, rentabilidad y las expectativas, que pueden variar según el nivel de desarrollo de una empresa en su inserción en los mercados internacionales, en las primeras etapas podría ser más relevante con los objetivos de ventas, y en los posteriores etapas las medidas de participación en los mercados (SOUSA, 2004, p. 8 e 14).

Diversas investigaciones empíricas sobre la medición del resultado exportador de las organizaciones, evalúan que se deberían incluir medidas económicas, indicadores de naturaleza objetiva, y estratégicos como medidas no económicas y genéricas, de naturaleza subjetiva, por la inter relación y complementariedad de dichos indicadores (STOIAN; RIALP; RIALP, 2011; SOUSA, 2004; KATSIKEAS; LEONIDOU; MORGAN, 2000). 


\section{CARACTERÍSTICAS ORGANIZACIONALES}

El tamaño de la empresa está ampliamente analizado en la literatura empírica, donde la dimensión de la empresa ejerce una influencia positiva en la actividad exportadora de una empresa. Sin embargo, no existe conclusiones claras entre el tamaño y el resultado exportador. Suárez Ortega y Álamo Vera (2005) han encontrado una relación positiva. Mientras que para Alonso y Donoso (2000) la relación es más ambigua, donde la teoría explica la relación en el momento de decidir exportar, pero existe una pluralidad de causas que deben gravitar en etapas posteriores de regularidad en las actividades internacionales (ALONSO; DONOSO, 2000, p. 52, 55).

En las PyMes exportadoras exitosas en América latina, se observó "[...] la existencia de umbrales de tamaño mínimos para emprender con éxito el negocio exportador" (ROBERT, 2007, p. 114).

Los resultados de exportación afecta la definición de las estrategias, en el grado de adaptación de producto (efectos indirectos), fijación de precios (efectos directos y totales) y distribución. Si el rendimiento ha sido satisfactorio, las empresas estarán en una mejor posición para desarrollar los resultados a largo plazo, y así, "[...] los resultados de exportación es un antecedente del compromiso de la empresa para la exportación" (LAGES; MONTGOMERY, p. 2004, 1203,1206).

Leonidou et al. (2002) consideran beneficios de la selección de una estrategia de adaptación del producto, en cuanto, el exportador evalúa sistemáticamente el comportamiento y necesidades específicas del mercado, generan innovaciones y logran productos superiores que pueden conducir a una mayor rentabilidad (LEONIDOU; KATSIKEAS; SAMIEE, 2002, p. 61).

Asimismo, en las empresas de Misiones, la mayor capacidad de transformación industrial en productos con mayor valor agregado son gravitantes con el resultado de la exportación (GUARROCHENA et al., 2013).

La innovación en los productos y procesos produce un mejoramiento o cambio de las estructuras y procesos, que conducen a un mejor desempeño. Lages, Silva y Styles (2009) destacaron a la innovación de productos como un determinante crítico de la ventaja diferencial internacional, que conducen a ventajas posicionales que impulsan la demanda y la posibilidades mejores precios, mejorando así los ingresos y el margen.

Estos autores señalaron que la innovación juega un papel importante en la mejora de los resultados económicos y produce un efecto significativo y positivo sobre el desempeño económico; sin embargo la calidad del producto no tuvo un efecto significativo en los resultados económicos, si bien no es suficiente para garantizar el desempeño económico en los mercados de exportación. podría ser un calificador en los mercados globales (LAGES; SILVA; STYLES, 2009, p. 53 e 59-60)

Las actividades de promoción es un modo de aprendizaje que genera acumulación de conocimientos, y se esperaría que una empresa que está dispuesta a adaptar su estrategia de promoción a las características del mercado debería obtener mejores resultados. 
Leonidou et al. (2002) afirman que la adaptación de la promoción (compuesta por propaganda, ventas, participación en ferias comerciales, visitas en el extranjero) exhibió una fuerte relación positiva con el rendimiento general de exportación, independientemente del tiempo, lugar y productos (LEONIDOU; KATSIKEAS; SAMIEE, 2002, p. 65).

\section{COMPROMISO EXPORTADOR EN LA GESTIÓN}

El compromiso está relacionado al esfuerzo y la asignación de recursos a las actividades de la gestión de la exportación, que facilitan la toma de decisiones de los directivos en los mercados. Diversos estudios empíricos, han encontrado que existe una relación positiva entre las características del compromiso exportador y los resultados internacionales (NAVARRO et al., 2010; LAGES; MONTGOMERY, 2004).

La experiencia en el mercado internacional, medida por la cantidad de años que permanece la empresa en los mercados, es considerada como un factor clave del nivel de compromiso y en particular en el desempeño exportador. El conocimiento e información de los mercados permite articular capacidades y recursos de la empresa, reduce la incertidumbre percibida de los mercados externos y contribuye a mejorar la capacidad de la empresa para administrar de manera eficiente las operaciones internacionales (LEONIDOU, 2004; SUÁREZ ORTEGA; ÁLAMO, 2005).

En el estudio de PyMes latinoamericanas, las posibilidades de un mejor desempeño internacional se incrementaron ante un tiempo mínimo de presencia en el mercado (ROBERT, 2007, p. 114).

La intensidad de las exportaciones, información cuantitativa sobre la propensión exportadora de la empresa -participación de las exportaciones sobre las ventas totales- está asociado al dinamismo exportador y al grado de compromiso alcanzado en los mercados externos, por asignar más recursos a las actividades de exportación en el largo plazo, que conduce a la implementación de estrategias efectivas y se traduce en un mejor rendimiento (LAGES; MONTGOMERY, 2004, p. 1188).

Una diversidad en la oferta comercial de productos de las empresas adaptada a las características de demanda internacional, tienen un mejor resultado exportador (LOZANO POSSO, 2004; SHOHAM, 1999, HITT; HOSKISSON; KIM, 1997).

Las PyMes más exitosas de países de América Latina priorizarían las acciones "[...] más proactivas relativas a productos y mercados; es decir, las que involucrarían mayores compromisos en términos de recursos" (ROBERT, 2007, p. 192).

La diversificación de mercados representa la presencia de las empresas en un mayor número de mercados de sus actividades en el exterior; y algunos autores han mostrado que las empresas más diversificadas internacionalmente tienen acceso a una mayor cantidad y diversidad de recursos (HITT; HOSKISSON; KIM, 1997, p. 795). 
Los mercados de destino de las exportaciones de las PyMes de madera de Misiones, reflejan un comportamiento diferente respecto a la demanda de productos según su nivel de transformación industrial y/o valor agregado y por ende de precios. Los mercados de América Latina son demandantes de productos de menor transformación industrial y en pequeñas cantidades. Los mercados de EE.UU., países europeos y otros son de una demanda más especializada y de precios (GUARROCHENA et al., 2013).

Las inversiones en los aspectos tecnológico-productivo, de gestión y comercialización, dirigidas al desarrollo exportador son determinantes de la capacidad innovativa de las empresas, que generan factores diferenciadores de ventajas competitivas para mejorar sus posibilidades y posiciones en los mercados. En las Pymes latinoamericanas, la adquisición de tecnología incorporada es el rubro que presenta mayor frecuencia, mientras el desarrollo de tecnología es menos significativo, pero las exportadoras exitosas realizan mayores esfuerzos en todas las categorías (MILESI; AGGIO, 2008, p. 36).

\section{CARACTERÍSTICAS DEL ENTORNO}

Las empresas perciben en el entorno, barreras y obstáculos externos, que aparecen por la incertidumbre propia del mercado nacional e internacional, que impactan sobre su comportamiento estratégico y, en definitiva, en sus resultados internacionales.

Las barreras a la exportación, en general, tienen un efecto negativo sobre los resultados internacionales (ESCANDÓN; HURTADO; CASTILLO, 2013; GARCIA; AVELLA, 2007; JULIAN Y AHMED, 2005).

Jiménez et al. (2013) demostró la existencia de una relación negativa y significativa entre las barreras percibidas y la intensidad exportadora, y que sería igual en empresas con diferentes experiencias en la actividad exportadora. Asimismo estos autores revelan que en escenarios de baja y alta turbulencia, "[...] las empresas más innovadoras son las que, probablemente, sean capaces de afrontar el reto de la internacionalización con una menor percepción de obstáculos" (JIMÉNEZ et al., 2013, p. 103).

En esta orientación, las percepciones de los directivos de empresas exportadoras de Misiones, Argentina, frente a barreras dentro de las fronteras, actúan como obstáculos a la permanencia en la actividad exportadora, dado que impactan sobre la productividad de la organización y competitividad de la actividad, y por ende, en los resultados de la exportación (GUARROCHENA, 2011).

\section{TIPO DE ESTRATEGIA IMPLEMENTADA}

Diversos estudios demuestran la aplicación de la tipología Miles y Snow en organizaciones para identificar patrones estratégicos con diferencias de grado de influencia 
sobre el desempeño y su influencia conjunta. En la Tabla $\mathrm{N}^{0} 1$ se resumen aportes de la literatura en los alcances operativos de los perfiles estratégicos.

Tabla 1 - Definiciones Operativas de los Perfiles Estratégicos de Miles y Snow.

\begin{tabular}{|c|c|c|c|c|}
\hline & Exploradora & Analizadora & Defensiva & Reactiva \\
\hline $\begin{array}{l}\text { Gestión } \\
\text { estratégica de } \\
\text { los productos- } \\
\text { mercados }\end{array}$ & $\begin{array}{l}\text { Amplio y en } \\
\text { expansión continua } \\
\text { del dominio } \\
\text { producto-mercado. } \\
\text { Desarrollo y } \\
\text { diversifi-cación de } \\
\text { mercados. } \\
\text { Buscan nuevas } \\
\text { oportunidades de } \\
\text { mercado mediante } \\
\text { procesos de } \\
\text { innovación y } \\
\text { desarrollo de } \\
\text { productos. } \\
\text { Activo en el cambio. } \\
\text { Orientado al } \\
\text { mercado y el } \\
\text { entorno. }\end{array}$ & $\begin{array}{l}\text { Mantiene una base } \\
\text { relativamente estable de } \\
\text { productos y mercados, } \\
\text { y al mismo tiempo } \\
\text { desarrolla de forma } \\
\text { selectiva nuevos } \\
\text { productos y mercados, } \\
\text { tratando de imitar a las } \\
\text { empresas que ya los } \\
\text { desarrollaron y tuvieron } \\
\text { éxito. } \\
\text { Son una simbiosis al } \\
\text { actuar de un modo } \\
\text { defensivo o explorador } \\
\text { dependiendo del } \\
\text { entorno y del equilibrio } \\
\text { eficiencia-innovación } \\
\text { que requieran. } \\
\text { Orientado a la } \\
\text { competencia }\end{array}$ & $\begin{array}{l}\text { Concentrando en un } \\
\text { estrecho y limitado } \\
\text { ámbito del producto- } \\
\text { mercado. } \\
\text { Orientada } \\
\text { internamente y } \\
\text { enfatizan en la } \\
\text { reducción de costes y } \\
\text { el incremento de la } \\
\text { eficiencia. } \\
\text { Basado en su dominio } \\
\text { mercado y cuidadoso. } \\
\text { Expertos en un área } \\
\text { determinada. } \\
\text { No buscan nuevas } \\
\text { oportunidades fuera } \\
\text { de su negocio, sino } \\
\text { que tratan de proteger } \\
\text { su cuota de mercado. }\end{array}$ & $\begin{array}{l}\text { Irregular y } \\
\text { transitorio en } \\
\text { producto-mercado. } \\
\text { Carecen de una } \\
\text { estrategia } \\
\text { consistente y clara } \\
\text { Esporádico y } \\
\text { dominado por temas } \\
\text { específicos. }\end{array}$ \\
\hline $\begin{array}{l}\text { Gestión } \\
\text { operativa de } \\
\text { los sistemas } \\
\text { de producción } \\
\text { y distribución } \\
\text { de productos }\end{array}$ & $\begin{array}{l}\text { Liderazgos } \\
\text { tecnológicos y } \\
\text { realizan fuertes } \\
\text { inversiones en } \\
\text { tecnología. } \\
\text { Actúan rápidamente } \\
\text { ante tendencias } \\
\text { emergentes del } \\
\text { entorno y suelen } \\
\text { propiciar cambios } \\
\text { en el sector. }\end{array}$ & $\begin{array}{l}\text { Siguen una estrategia } \\
\text { intermedia y son más } \\
\text { cuidadosas que las } \\
\text { exploradoras, e } \\
\text { invierten en tecnología } \\
\text { después de un profundo } \\
\text { análisis de } \\
\text { posibilidades }\end{array}$ & $\begin{array}{l}\text { Eficiencia en costos. } \\
\text { Necesitan pocos } \\
\text { ajustes en tecnología, } \\
\text { estructura o procesos. } \\
\text { Son más } \\
\text { conservadoras y } \\
\text { enfocan inversiones } \\
\text { en áreas directamente } \\
\text { relacionada con su } \\
\text { línea de negocio. }\end{array}$ & $\begin{array}{l}\text { Normalmente actúa } \\
\text { forzada por las } \\
\text { presiones del } \\
\text { entorno y de la } \\
\text { competencia } \\
\text { Desarrollo de } \\
\text { proyectos. } \\
\text { Aplicaciones } \\
\text { tecnológicas } \\
\text { cambiantes. }\end{array}$ \\
\hline
\end{tabular}

Fuente: Adaptado de García Pérez de Lema; Martínez; Aragón Sánchez (2009); García Perez de Lema; Gallego (2006); Gimenez et.al.(1999)

\section{METODOLOGÍA}

La revisión de las principales investigaciones centradas en la actividad exportadora de la empresa se han dirigido a investigar las características estructurales y organizativas de la empresa para analizar su influencia sobre el resultado exportador, y pone de manifiesto la relevancia de un conjunto de factores, a la hora de inhibir o facilitar la actividad exportadora de la empresa. Sin embargo, en la relación con el entorno, las organizaciones producen cambios en el tiempo y adaptan las estrategias para responder a cambios del entorno. 
Desde los modelos de gestión estratégica, Lages y Souza (2010, p. 4) señalan que "[...] el paradigma basado en los recursos y el paradigma de contingencia, proporcionan la base para la clasificación de los factores determinantes del comportamiento de las exportaciones en los factores internos y externos". Los determinantes internos se justifican por la teoría basada en los recursos -focaliza en cómo la ventaja competitiva sostenida es generado por el paquete exclusivo de recursos en el núcleo de la empresa-, mientras que los determinantes externos son soportados por la teoría de contingencia- sugiere que los factores ambientales influyen en las estrategias de la empresa y los resultados de exportación (LAGES; SOUSA, 2010).

Por ello, la perspectiva adoptada en este estudio es de los recursos y capacidades organizacionales que dirige su atención al interior de la empresa, y describe su compromiso evolutivo con el entorno en un enfoque de contingencia.

El propósito principal es identificar los rasgos diferenciales de las estrategias competitivas para alcanzar mejores resultados de exportación en Pequeñas y Medianas Empresas de la industria de la madera de Misiones, Argentina; mediante el examen de las relaciones de las estrategias implementadas en los resultados de exportación.

El marco conceptual aplicado se basa en un enfoque sistémico y holístico de las organizaciones, que interpreta las inter relaciones entre los componentes de las estrategias que inducen el desarrollo y el compromiso asumido con el resultado de la actividad de exportación.

El análisis propuesto integra las características de la organización, el compromiso de exportación, las características del entorno, y los tipos de estrategias implementadas, que influyen, directa e indirectamente, en el resultado exportador. Se evalúan los tipos de estrategias competitivas con orientación al mercado externo, de acuerdo a la tipología de Miles y Snow (1978).

Gráfico 1 - Enfoque conceptual y dimensiones de análisis

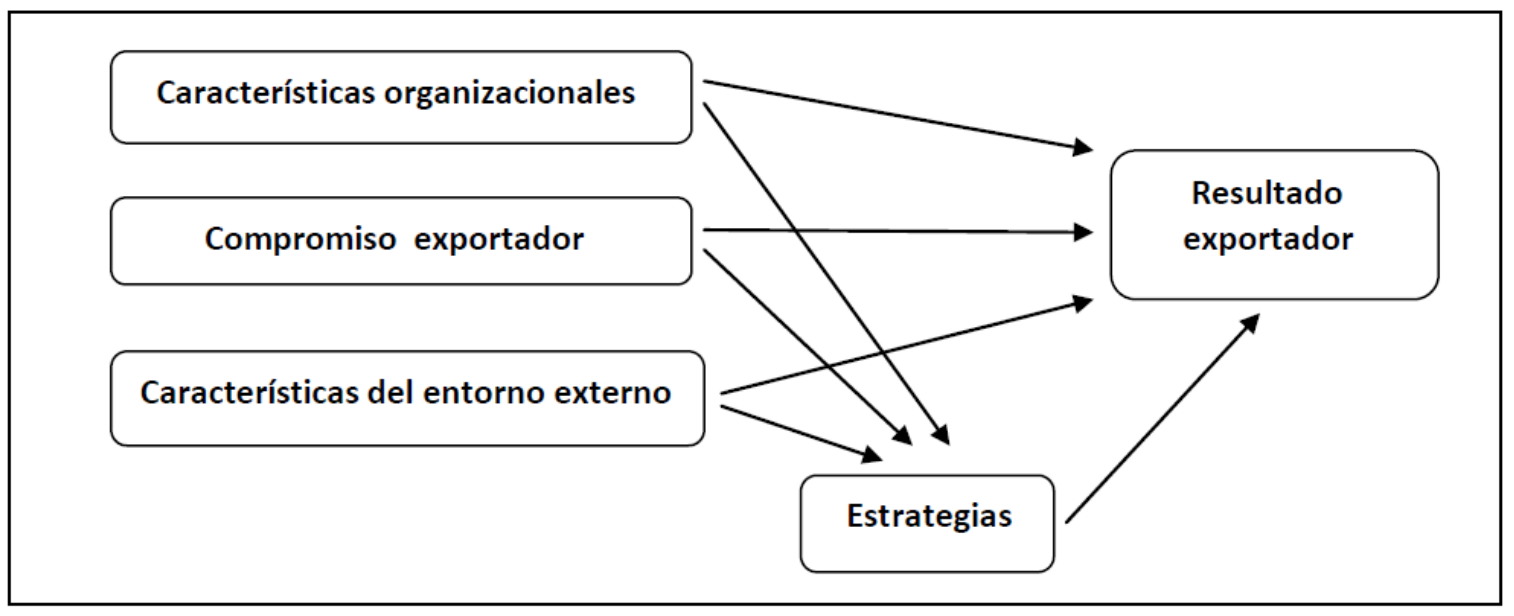

Fuente: Elaboración Propia

DRd - Desenvolvimento Regional em debate (ISSNe 2237-9029) 
Las estrategias de exportación son abordadas según la caracterización de las estrategias implementadas, en diferentes tipos: explorador, analizador, defensor y reactivo; en relación con la forma en la que se administran los factores internos específicos de productomercado, que incluye el desarrollo y conocimiento de producto-mercado y experiencia en el mercado externo, y las estructuras y los procesos de la gestión de la empresa necesarios para la ejecución de cada tipo de estrategia.

Las variables específicas fueron relativas a: Productos (desarrollo nuevos productos; diversidad de productos; innovación productos de mayor valor agregado y segmentos de alto precio); Mercados (diversificación y distancia mercados; Tecnología y procesos: (inversión en tecnología; mejora de procesos; aplicación sistemas de calidad; innovación procesos; Capacitación personal; actividades de promoción); Experiencia exportadora (permanencia y continuidad en el mercado externo).

Esto permite evaluar las respuestas estratégicas de las empresas que pertenecen a cada tipo estratégico sobre su desempeño y las implicaciones para el resultado exportador.

\section{MÉTODO Y TÉCNICAS}

La investigación es descriptiva y correlacional, de acuerdo a datos cuantitativos económicos-comerciales de la serie 2006-2011 y variables cuali-cuantitativas de una muestra de PyMes, del relevamiento realizado en el año 2011.

La metodología de la investigación es la siguiente:

a) Para la identificación de los tipos de estrategias implementadas, se analizó los perfiles estratégicos teóricos y las nuevas evidencias de los antecedentes empíricos para seleccionar las variables operativas que involucran una actitud hacia el grado de innovación (producto-mercado). Se aplica un análisis descriptivo, cuali y cuantitativo, mediante el método de indicadores objetivos, por análisis empírico de datos, que captan las dimensiones estratégicas, mediante la identificación de variables en estudio, en la muestra de PyMes, a través de estadísticas descriptivas. El contenido y la identificación de los perfiles por empresa fueron validadas simultáneamente por un panel de profesionales expertos en gestión exportadora de la madera.

b) Para analizar la posible relación lineal existente entre los pares de variables que resultan significativas con el resultado exportador, se utiliza el coeficiente correlación que se define, en general, como un instrumento estadístico que mide el grado de asociación lineal entre dos variables (LAHURA, 2003, p. 17).

Debido al tamaño de la muestra, se decidió observar indicios de las relaciones existentes entre las variables planteadas, haciendo uso de la matriz de correlación; y se realizó un sencillo modelo regresión múltiple para cuantificar estas relaciones. 
Los datos comerciales por empresas, de productos de madera aserrada y sus manufacturas desde la provincia de Misiones, se sistematizó con referencia al período 20062011, de la base de datos Nosis de Exportadores Argentino.

Característica de la muestra

El estudio de caso se focaliza en las PyMes que concretan por su cuenta las ventas al mercado externo y cuyas industrias están localizadas en Misiones. En el año 2010, constituían 39 PyMes, representando el 12,50\% del valor total de exportación de las industrias en Misiones, dado la presencia de una mega empresa que concentra el resto de la oferta exportable.

Se seleccionó una muestra por juicio de 20 PyMes exportadoras de productos de madera sólida y estructural de madera de bosques implantados y ponderado por el tamaño de la capacidad productiva industrial y facturación en las ventas anuales. Se excluyen las empresas productores-exportadoras, principalmente de productos de características diferenciales en tecnologías y mercado; como madera nativa, chapas, terciados, y pellets.

La muestra seleccionada representa, del total de PyMes exportadoras, localizadas en Misiones, el 51\% de las empresas y el 86,82\% del valor total de exportación, en el año 2010.

El criterio utilizado en la segmentación de la muestra fue por la técnica de fijación proporcional, de acuerdo a la capacidad industrial $\mathrm{en}^{3}$ mensuales, registro de los Censos industriales de la madera de Misiones (SIFIP, 2010), que evalúa su potencialidad en términos de oferta productiva en pequeñas, medianas, medianas-grandes y grandes El rango superior fue discriminado en función de la capacidad de producción de la mega empresa, para evitar los sesgos en la estratificación por tamaño.

Cuadro 1 - Estratificación de la Muestra de PyMes exportadoras, según tamaño por capacidad industrial, 2010

\begin{tabular}{|l|l|l|l|l|l|}
\hline \multirow{2}{*}{ PyMes exportadoras, localizadas en Misiones } & & $\begin{array}{l}\text { Cantidad de } \\
\text { empresas } \\
\text { Año } 2010\end{array}$ & \multicolumn{2}{l|}{$\begin{array}{l}\text { Tamaño PyMes } \\
\text { capacidad de producción industrial (en } \\
\mathrm{m}^{3} \text { ) }\end{array}$} \\
\cline { 2 - 6 } & & $\begin{array}{l}\text { Pequeña } \\
\text { Hasta } \\
600\end{array}$ & $\begin{array}{l}\text { Mediana } \\
+600- \\
1.900\end{array}$ & $\begin{array}{l}\text { Mediana } \\
- \text { Grande } \\
+1.900- \\
3.500\end{array}$ & $\begin{array}{l}\text { Grande } \\
+3.500- \\
6000\end{array}$ \\
\hline $\begin{array}{l}\text { Total industrias de productos de madera de } \\
\text { bosques implantados }\end{array}$ & 31 & $13 \%$ & $58 \%$ & $22 \%$ & $7 \%$ \\
\hline Total Muestra & 20 & $15 \%$ & $55 \%$ & $20 \%$ & $10 \%$ \\
\hline
\end{tabular}

Fuente: Adaptado en base clasificación SIFIP (2010) 
Este segmento de PyMes representan el 64,50\% de las empresas y el 95,51\% del valor total de exportación, del año 2010.

Las empresas bajo estudio, se ubican en la categoría de PyMes según el nivel facturación de ventas totales anuales, en el sector industrial, de acuerdo a la normativa de Argentina (SEPYME, 2010). A los fines de compatibilizar el criterio de selección de empresas de la muestra, se adecuó el segmento de facturación anual de la mediana empresa.

Cuadro 2 - Estratificación de la Muestra por tamaño según facturación anual, 2010

\begin{tabular}{|c|c|c|c|c|}
\hline & \multirow[t]{2}{*}{$\begin{array}{c}\text { Cantidad de empresas } \\
\text { Año } 2010\end{array}$} & \multicolumn{3}{|c|}{$\begin{array}{l}\text { Tamaño PyMes } \\
\text { Facturación (en millones de pesos) }\end{array}$} \\
\hline & & $\begin{array}{l}\text { Pequeña } \\
+1,8 \text { a } 10,3\end{array}$ & $\begin{array}{l}\text { Mediana } \\
+10,3 \text { a } 36,5\end{array}$ & $\begin{array}{l}\text { Mediana }+ \\
+36,5 \text { a } 82,2\end{array}$ \\
\hline Total Muestra & 20 & $45 \%$ & $35 \%$ & $20 \%$ \\
\hline
\end{tabular}

Fuente: Adaptado en base clasificación SEPYME (2010)

\section{RESULTADOS}

\section{ANÁLISIS DESCRIPTIVO DE LAS PYMES EXPORTADORAS}

La dinámica de las exportaciones de las empresas en estudio, fue muy dispar a los largo del período en estudio. Como se muestra en el Gráfico № 2, en el período 2007 -2009, las ventas externas han caído por la crisis financiera que se tradujo a la economía real y que tuvo consecuencias desfavorables para el sector forestal de la provincia de Misiones, ya que su principal país comprador son los Estados Unidos, país donde se originó la crisis que afectó al sector inmobiliario y de la construcción.

Si bien en el año 2010 y 2011 se recuperaron las exportaciones de las PyMes, no lograron alcanzar los valores del año 2008, que registró el impacto de la crisis financiera mundial.

Las Pymes en la muestra analizada son medianas empresas (55\%) y el resto son pequeñas, según su nivel de facturación anual. En la clasificación sectorial por su capacidad de producción industrial instalada, pequeñas un $15 \%$, más de la mitad empresas medianas (55\%), mediana-grande un $20 \%$ y grandes un $10 \%$. En cuanto a la antigüedad en la actividad productiva sectorial, el promedio es de 24 años, y no existe diferencias con el tamaño. 
Gráfico 2 - Evolución de las exportaciones de PyMes en Misiones, en dólares

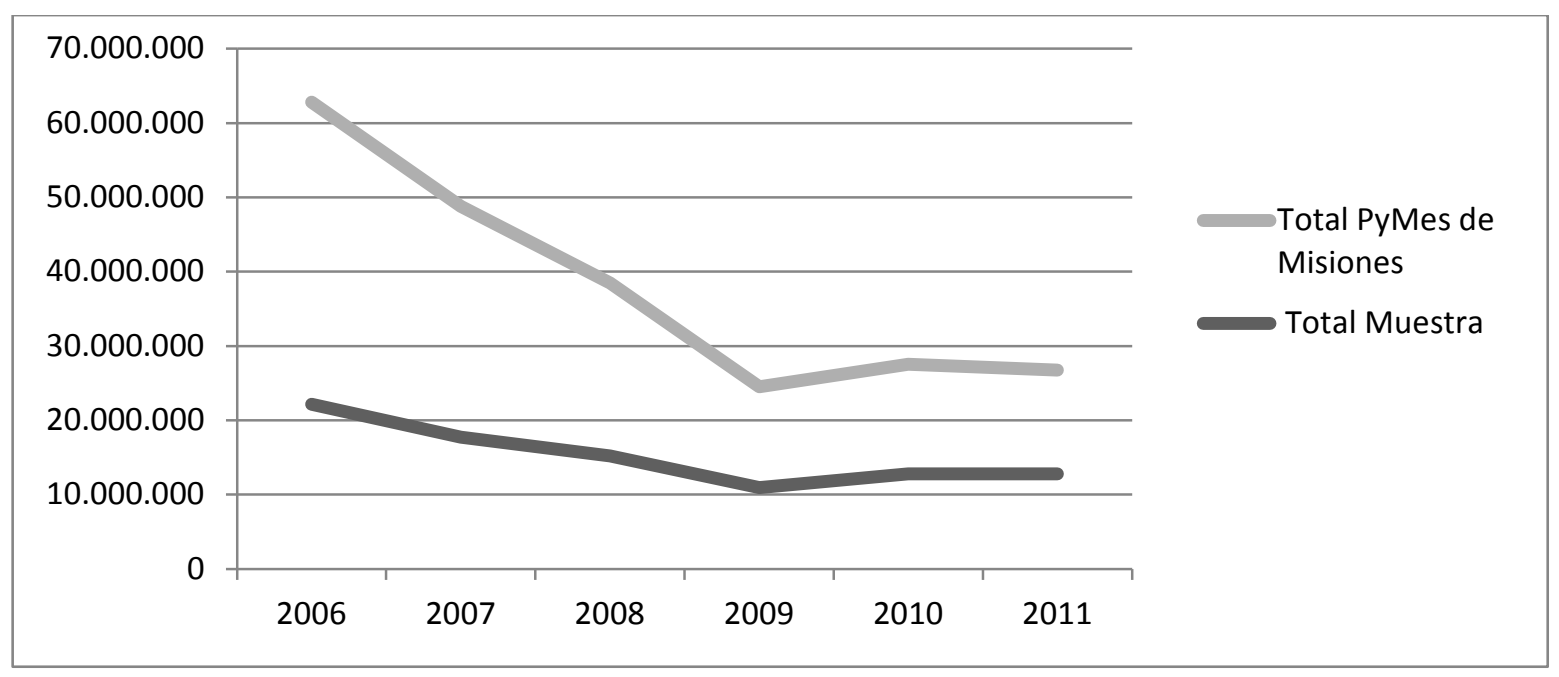

Fuente: Elaboración propia en base a datos de Nosis

Casi el tercio de las empresas iniciaron su experiencia exportadora en el período exante de la devaluación del año 2002, con más de 10 años; y la mayoría de las empresas tienen entre 7 y 10 años de experiencia iniciados en el período de expansión post devaluación. Estas empresas comenzaron a exportar, en promedio, a los 15 años desde que se inicio en la actividad en el sector; las empresas medianas fueron las que menos años tardaron en ingresar al negocio exportador, y son las más jóvenes.

La mayoría de las PyMes (55\%) destina menos del 10\% de su ventas totales al mercado externo y el $40 \%$ de medianas a grandes entre un $26-50 \%$ y una única empresa mediana exporta más del $50 \%$ de su producción.

La totalidad de las PyMes poseen el requisito básico tecnológico de calidad de la madera, que es el secado de madera en cámara, última fase proceso industrial, para cubrir el stock de materia prima de calidad. Las inversiones tecnológicas-productivas, actividades de vinculación y promoción, diversificación de productos y mercados de destinos, es mayor en las empresas de mayor tamaño.

\section{PERFILES ESTRATÉGICOS}

En el análisis de perfiles estratégicos, se identificaron un $15 \%$ de las Pymes exportadoras en estudio como exploradoras, un 35\% como analizadoras y el 50\% restante como defensoras, y no se encontró ninguna empresa con características de reactivas.

Las exploradoras son empresas de mayor tamaño (mediana- grande y grande) por su capacidad productiva y representan el $61,27 \%$ de las ventas totales de exportación de la muestra en el año 2010. Las analizadoras son en su mayoría medianas empresas (71\%) y de mayor capacidad productiva un $29 \%$, representan el $30,9 \%$ de las ventas. Y las empresas 
defensoras son todas las pequeñas (30\%), la mayoría medianas empresas $(60 \%)$ y 1 mediana grande, participan con el 7,83\% de las ventas.

El rendimiento promedio de las ventas totales de exportación, en el año 2010, es mayor en las empresas exploradoras.

\section{APLICACIÓN DEL MODELO DE REGRESIÓN}

A través de la aplicación de un modelo de regresión múltiple se busco determinar qué tipo de variables de las dimensiones de las características de la organización, del compromiso exportador, características del entorno y los tipos de estrategias implementadas explicarían el resultado exportador. La Tabla $\mathrm{N}^{\circ} 2$ detalla las variables de tipos cuali-cuantativas, para recoger las relaciones de las características descriptas anteriormente.

Se consideró la variable dependiente como el resultado de las Exportaciones en valor de ventas en millones de dólares (Exp). y las variables independientes en un análisis de 4 variables: a) características de la organización (compuesta por cuatro indicadores: tamaño, cantidad de productos de mayor valor agregado, innovación en productos de mayor valor agregado, actividades de promoción y vinculación; b) compromiso exportador (compuesta por 7 indicadores: experiencia, intensidad, diversidad de productos y mercados de destino, distancia de los mercados de destino, inversiones en tecnologías y procesos, capacidad industrial, proceso industrial de calidad de la madera); c) características del entorno (compuesta por 2 indicadores: barreras u obstáculos del mercado interno nacional y externo); d) Estrategias (compuesta por 4 tipos de estrategias: exploradora, analizadora y defensora).

Para realizar el análisis entre las variables, se consideró el año 2010, dado que fue el único año en el cual las 20 empresas relevadas han exportado en el período 2006-2011.

Cabe resaltar que se ha trabajado con una muestra pequeña de 20 empresas, y considerando las restricciones estadísticas, se decidió observar indicios de las relaciones existentes entre las variables planteadas, haciendo uso del análisis de una matriz de correlación.

\section{DETERMINANTES DEL RESULTADO EXPORTADOR Y ASOCIACIÓN CON LAS VARIABLES}

El análisis los determinantes del resultado exportador y si existe una relación o asociación lineal entre las variables independientes y el resultado, se observa en la matriz de correlación calculada. Una lectura conjunta de los mismos se puede revisar en la Tabla $\mathrm{N}^{\circ} 3$. Esta Matriz muestra la siguiente información: 
-Los resultados de la exportación (EXP) tienen una relación negativa con las empresas cuya facturación anual es pequeña (PEQ) y mediana (MED), siendo positiva su relación con las empresas que tienen un nivel mayor de facturación entre las Medianas MED+

-Una mayor participación en actividades de promoción (ferias, visitas de compradores y contactos internacionales) que vinculen a la empresa con el mercado externo (CTDAATCV) mostraría un aumento en el volumen exportado. Existe una relación positiva entre estas variables.

- Respecto a la intensidad exportadora, medido por el porcentaje de ventas al mercado exterior, si supera el $10 \%$ de sus ventas al mercado externo (INTEN1125, INTEN2650), tendría una relación positiva con los resultados logrados.

-La relación existente entre las empresas con una experiencia exportadora de más de 10 años (MER10), o sea con una permanencia en el mercado anterior al período de devaluación del año 2002, tendrían un relación positiva con los resultados

Las empresas que han iniciado su exportación en el período posterior, en condiciones económicas favorables de la economía nacional y de expansión del comercio internacional, la relación con el volumen exportado sería negativa (MER910). Esto implicaría que el fortalecimiento del volumen exportado se logra después de los 10 años. Esto se podría deducir de la variable (MER10) ya que presenta un coeficiente de correlación positivo.

-Una mayor cantidad en variedad de productos exportados (PROEXPO), en productos de mayor transformación y/o valor agregado (CTDPROIN) y aquellas empresas que exportan y han innovado en productos con mayor agregado y precio en el mercado internacional (INNMAY) mostrarían una asociación con un mayor aumento de volumen exportado. 
Tabla 2 - Clasificación de las variables y descriptores

\begin{tabular}{|c|c|c|}
\hline Variables & Indicadores & Códigos y Descriptores \\
\hline $\begin{array}{lll}\begin{array}{l}\text { Resultado } \\
\text { exportación }\end{array} & \text { de la } \\
\end{array}$ & Ventas de exportación, tamaño de los ingresos de exportación en valor en dólares- U\$S, del año 2010 & EXP \\
\hline \multirow[t]{4}{*}{$\begin{array}{l}\text { Características } \\
\text { Organizacionales }\end{array}$} & Tamaño de empresa por nivel de facturación, adaptada según clasificación SEPYME ( 2010 ) & $\begin{array}{l}\text { PEQ Pequeña, de }+1,8 \text { a } 10,3 \text { Millones de pesos; } \\
\text { MED Mediana, }+10,3 \text { a } 32,25 \text { Millones de pesos; } \\
\text { MED+.Mediana-Grande, de }+32,5 \text { a } 82,2 \text { Millones de pesos }\end{array}$ \\
\hline & $\begin{array}{l}\text { Actividades de promoción y vinculación, según nivel de participación e intensidad total y por actividad de presencia a } \\
\text { ferias, recepción de visitas de compradores a planta industrial y contactos comerciales por Internet }\end{array}$ & $\begin{array}{l}\text { ferNac }=1 \text { Feria nacional; } \quad \text { FERINTER }=1 \text { Feria internacional } ; \\
\text { VINAC }=1 \text { Visita compradores nacionales; VINTER internacionales }=1-\text {; } \\
\text { CNAC }=1 \text { Contactos comerciales Nacionales; CINTER }=1 \text { internacionales; } \\
\text { Cantidad total de actividades de promoción }- \text { CTDAATCV. }\end{array}$ \\
\hline & $\begin{array}{l}\text { Productos exportables con mayor transformación industrial y/o valor agregado-VA, en el período 2006-2011, } \\
\text { indirectamente la capacidad industrial con productos más competitivos en el mercado externo }\end{array}$ & CTDPROIN Cantidad productos de mayor transformación y/o VA \\
\hline & $\begin{array}{l}\text { Innovación con productos con mayor valor agregado, identifica la capacidad de innovación en el desarrollo de productos } \\
\text { diferenciales de la competencia local, y de mayor especialización y precios }\end{array}$ & INNMAY $=1$ si existe innovación con mayor valor agregado \\
\hline \multirow[t]{7}{*}{ Compromiso exportador } & $\begin{array}{l}\text { Experiencia exportadora, años de actuación en los mercados externos; identifica la trayectoria exportadora de las empresas, } \\
\text { vinculada a los sucesos económicos que afectaron las condiciones para la entrada a los mercados internacionales: las } \\
\text { empresas con más antigüedad, +de } 10 \text { años, exportaban antes de la devaluación del peso en el año } 2001 \text {, que generaron } \\
\text { condiciones de expansión de las exportaciones y mejoras de competitividad. El resto de las empresas ingresa en el período } \\
\text { pos-crisis, a partir del año } 2002\end{array}$ & $\begin{array}{l}\text { MER910 }=1 \text { si experiencia } 9 \text { a } 10 \text { años ex post devaluación2002 } \\
\text { MER10 }=1 \text { si experiencia más de } 10 \text { años ex ante devaluación } 2002\end{array}$ \\
\hline & Intensidad Exportadora, proporción de las ventas de exportación sobre las ventas totales de la empresa & $\begin{array}{l}\text { INTEN }=1 \text { menor a } 10 \% \\
\text { INTEN1125 }=1 \text { si intensidad está entre } 11 \text { y } 25 \% \\
\text { INTEN2650 }=1 \text { si intensidad está entre } 26 \text { y } 50 \%\end{array}$ \\
\hline & Diversidad de productos exportados, cantidad de variedad de productos comercializados, período 2006-2011 & PRODEXPO = cantidad productos \\
\hline & Diversificación mercados de destino, cantidad de mercados, período 2006-2011 & MERCEXPO = cantidad mercados \\
\hline & $\begin{array}{l}\text { Distancia de los mercados de destino, desde Misiones según características de la demanda de los mercados } \\
\text { Los rangos se establecen según el porcentaje de ventas mayor a diferentes mercados }(+60 \%) \text {. } \\
\text { Los mercados de menor distancia, son los más cercanos a Misiones, considerando los países de América Latina, cuya } \\
\text { demanda se caracteriza por productos de poca transformación y menor valor agregado. } \\
\text { Los mercados de mayor distancia, son mercados de demanda más especializada y precio. }\end{array}$ & $\begin{array}{l}\text { MENDIST }=1 \text { menor distancia } \\
\text { Mayordistancia }=1 \text { mayor distancia }\end{array}$ \\
\hline & $\begin{array}{l}\text { Inversiones en tecnologías y procesos (capacidad tecnológica) } \\
\text { Se consideran inversiones en los últimos } 8 \text { años de: ampliación capacidad industrial en equipamiento y maquinaria; nuevas } \\
\text { líneas de producción; mejoramiento de procesos; aplicación de sistemas de calidad; certificaciones de grado de la madera, } \\
\text { norma cadena custodio; y capacitación del personal }\end{array}$ & TOTALINVE $=$ total inversiones \\
\hline & Proceso industrial de calidad de la madera: Capacidad de utilización de la cámara de secado, en porcentaje, & PORCSECA $=\%$ secado \\
\hline \multirow[t]{2}{*}{$\begin{array}{l}\text { Características } \\
\text { entorno }\end{array}$} & $\begin{array}{l}\text { Barreras del mercado interno Percepción del empresario de los obstáculos en el mercado nacional, como barreras } \\
\text { económicas, comerciales, financieras, administrativas y operativas. }\end{array}$ & $\begin{array}{l}\text { INAC: } 1=\text { importancia barrera nacional } \\
\text { PINAC: } 1=\text { poca importancia barrera nacional }\end{array}$ \\
\hline & $\begin{array}{l}\text { Barreras del mercado externo: Percepción del impacto de barreras en los mercados externos, como barreras arancelarias, } \\
\text { no arancelarias, políticas económicas, comerciales, administrativas y operativas del comercio exterior. }\end{array}$ & $\begin{array}{l}\text { II }=1 \text { importancia barrera internacional } \\
\text { PII }=1 \text { poca importancia barrera internacional }\end{array}$ \\
\hline Estrategias & $\begin{array}{l}\text { Tipo de estrategia implementada en entorno inestable y no dinámico, exploradoras, analizadoras y defensivas. Esta } \\
\text { variable aplica los tipos de estrategias( Miles y Snow, 1978), por características de proceso e innovación producto- mercado }\end{array}$ & $\begin{array}{l}\text { EXPLO }=1 \text { si tiene estrategia exploradora } \\
\text { ANALIZ }=1 \text { si tiene estrategia analizadora } \\
\text { DEFENS }=1 \text { si tiene estrategia defensiva }\end{array}$ \\
\hline
\end{tabular}

DRd - Desenvolvimento Regional em debate (ISSNe 2237-9029)

v. 5 , n. 1, p. 111-139, jan./jun. 2015 
-Una mayor diversificación de los destinos de exportación (MERCEXPO) y con mayor participación en los mercados de mayor distancia (Mayordistancia), segmentos compradores de productos de mayor transformación y/o valor agregado y de precios estarían correlacionados positivamente con las exportaciones de las empresas involucradas. Los destinos a mercados más cercanos (MENDIST), segmentos de productos de menor valor agregado y precios, no tendría una relación positiva con los resultados. Sin embargo, un segmento de medianas empresas mostraría una relación positiva

-Cuanto mayores inversiones en maquinarias, en líneas de producción, procesos, sistemas de calidad y capacitación del personal (TOTALINVE) haya realizado la empresa para el desarrollo exportador, mayor será el volumen exportado.

- La relación entre el grado de utilización de la cámara de secado (PORCSECA) con el volumen exportado sería negativo. La cámara de secado de madera es el proceso industrial tecnológico, uno de los indicadores de calidad de la madera, según opinión de expertos. Todas las empresas poseen esta tecnología y está incorporado en todos los niveles de la variable (EXP) con el 93\% de capacidad de utilización.

-La percepción del impacto de mayores barreras u obstáculos nacionales al desarrollo exportador (INAC) presentarían una relación negativa con el resultado, Sin embargo una menor percepción de esas barreras (PINAC) correlacionan positivamente con los volúmenes exportados. Evidenciaría como las condiciones del entorno nacional, pueden afectar la competitividad del negocio y a las empresas.

-La percepción de impactos menores de barreras u obstáculos de los mercados internacionales en el desarrollo exportador (PII) presentarían una relación positiva con el resultado. Sin embargo una mayor percepción de esas barreras (II) correlacionan negativamente con los volúmenes exportados.

-Las empresas que implementan estrategias exploradoras (EXPLO), tienen una relación positiva con mayores resultados, y están vinculadas positivamente con: empresas de tamaño mediana-grande, de mayor facturación; cantidad de productos exportados $(0,6235)$; innovación en productos de mayor agregado y precios $(0,6078)$ : inversiones en tecnologías y procesos $(0,5408)$; desarrollo de productos de mayor transformación y valor agregado $(0,5145)$; actividades de promoción y vinculación $(0,4500)$; intensidad de exportación de $11-25 \%$ y 26-50\% $(0,3267$ y 0,3361); experiencia en el mercado más de 10 años, ex-ante devaluación 2002 $(0,3361)$; poca relevancia a barreras en los mercados externos $(0,3033)$; diversificación en mercados de mayor distancia $(0,2425)$; poca relevancia a obstáculos nacionales $(0,1400)$

-Las empresas que implementan estrategias defensivas (DEFENS), tienen una relación negativa con mayores resultados, y están vinculadas positivamente con: las empresas de tamaño pequeñas y medianas; mercados de menor distancia $(0,5774)$; experiencia en el mercado menor a 10 años, ex-post devaluación $2002(0,4000)$; intensidad de exportación menor de $10 \%(0,3015)$; alta relevancia a obstáculos nacionales $(0,2500)$; poca relevancia a las barreras en los mercados externos $(0,1048)$ 
-Las empresas que implementan estrategias analizadoras (ANALIZ), tienen una relación negativa con mayores resultados, y están vinculadas positivamente con: las empresas de tamaño pequeñas y medianas; diversificación en mayor cantidad de mercados $(0,4551)$; en mercados de mayor distancia $(0,4237)$; alta relevancia a las barreras en los mercados externos $(0,3407)$; desarrollo de productos de mayor transformación y valor agregado $(0,2568)$; experiencia en el mercado de más de 10 años $(0,2059)$; mayores inversiones $(0,1735)$; poca relevancia a obstáculos nacionales $(0,1572)$; cantidad de productos exportados $(0,1394)$; intensidad de exportación menor de de $10 \%(0,0316)$.

Tabla 3 - Coeficientes de correlación

\begin{tabular}{|c|c|c|c|c|c|c|c|}
\hline $\begin{array}{c}\text { EXP } \\
1,0000\end{array}$ & $\begin{array}{c}\text { PEQ } \\
-0,3135 \\
1,0000\end{array}$ & $\begin{array}{c}\text { MED } \\
-0,7401 \\
0,5000 \\
1,0000\end{array}$ & $\begin{array}{c}\text { ferNac } \\
0,6607 \text { EXP } \\
-0,2041 \text { PEQ } \\
-0,6124 \text { MED } \\
1,0000 \text { ferNac }\end{array}$ & $\begin{array}{c}\text { FERINTER } \\
0,1914 \\
0,0000 \\
-0,2182 \\
0,1336 \\
1,0000\end{array}$ & $\begin{array}{c}\text { VNAC } \\
-0,0163 \\
-0,2041 \\
0,1021 \\
0,0417 \\
0,0891 \\
1,0000\end{array}$ & $\begin{array}{c}\text { VINTER } \\
0,2194 \\
-0,2182 \\
-0,3273 \\
0,0891 \\
0,4286 \\
0,1336 \\
1,0000\end{array}$ & $\begin{array}{c}\text { CNAC } \\
-0,1051 \text { EXP } \\
-0,1005 \text { PEQ } \\
-0,0503 \text { MED } \\
0,0821 \text { ferNac } \\
0,2851 \\
\text { FERINTER } \\
-0,2872 \text { VNAC } \\
-0,2851 \\
\text { VINTER } \\
1,0000 \text { CNAC }\end{array}$ \\
\hline $\begin{array}{c}\text { CINTER } \\
0,1818 \\
0,2000 \\
0,0000 \\
0,0000 \\
0,4364 \\
\\
-0,2041 \\
0,0000 \\
0,3015 \\
1,0000\end{array}$ & $\begin{array}{c}\text { CTDATCV } \\
0,4335 \\
-0,1495 \\
-0,4111 \\
0,5187 \\
0,7013 \\
0,2441 \\
0,4404 \\
0,2930 \\
0,5232 \\
1,0000\end{array}$ & $\begin{array}{c}\text { CTDPROIN } \\
0,4070 \\
-0,6124 \\
-0,6124 \\
0,1667 \\
-0,0891 \\
0,2500 \\
0,5345 \\
-0,3282 \\
-0,2041 \\
0,2136 \\
1,0000\end{array}$ & $\begin{array}{c}\text { INNMAY } \\
0,6433 \text { EXP } \\
-0,4201 \text { PEQ } \\
-0,4901 \text { MED } \\
0,2287 \text { ferNac } \\
0,0306 \\
\text { FERINTER } \\
0,0572 \text { VNAC } \\
0,2750 \\
\text { VINTER } \\
-0,0985 \text { CNAC } \\
0,1400 \\
\text { CINTER } \\
0,3454 \\
\text { CTDATCV } \\
0,5145 \\
\text { CTDPROIN } \\
1,0000 \\
\text { INNMAY }\end{array}$ & $\begin{array}{c}\text { MER910 } \\
-0,3938 \\
0,4000 \\
0,2500 \\
-0,4082 \\
0,2182 \\
-0,2041 \\
0,2182 \\
-0,1005 \\
0,0000 \\
-0,1495 \\
-0,2041 \\
-0,4201 \\
1,0000\end{array}$ & $\begin{array}{c}\text { MER10 } \\
0,5216 \\
-0,4364 \\
-0,4910 \\
0,5791 \\
-0,1905 \\
-0,1336 \\
-0,0476 \\
0,0658 \\
0,0000 \\
0,2120 \\
0,3563 \\
0,6417 \\
-0,6547 \\
1,0000\end{array}$ & $\begin{array}{c}\text { INTES } \\
-0,5860 \\
-0,1005 \\
0,3015 \\
-0,4924 \\
-0,5044 \\
0,2872 \\
-0,1535 \\
0,0101 \\
-0,3015 \\
-0,3681 \\
0,1231 \\
-0,1830 \\
0,1005 \\
-0,2851 \\
1,0000\end{array}$ & $\begin{array}{c}\text { INTEN1125 } \\
0,0921 \text { EXP } \\
-0,0000 \text { PEQ } \\
-0,2500 \text { MED } \\
0,0680 \text { ferNac } \\
0,5092 \\
\text { FERINTER } \\
-0,0680 \text { VNAC } \\
0,2182 \\
\text { VINTER } \\
-0,3015 \text { CNAC } \\
0,0000 \\
\text { CINTER } \\
0,1495 \\
\text { CTDATCV } \\
0,0680 \\
\text { CTDPROIN } \\
-0,1400 \\
\text { INNMAY } \\
0,3333 \\
\text { MER910 } \\
-0,2182 \\
\text { MER10 } \\
-0,3685 \text { INTES } \\
1,0000 \\
\text { INTEN1125 }\end{array}$ \\
\hline inten26-50 & PRODEXPO & MERCEXPO & MENDISTA & $\begin{array}{l}\text { mayorDISTAN } \\
\text { CIA }\end{array}$ & totalinve & PORCSECA & INAC \\
\hline 0,5065 & 0,7473 & 0,5011 & $-0,2973$ EXP & 0,2973 & 0,5849 & $-0,1313$ & $-0,3711$ EXP \\
\hline$-0,0000$ & $-0,4627$ & $-0,2233$ & $-0,1155$ PEQ & 0,1155 & $-0,1576$ & $-0,0982$ & 0,2500 PEQ \\
\hline$-0,2182$ & $-0,7663$ & $\begin{array}{l}-0,4961 \\
05570\end{array}$ & $\begin{array}{l}0,2887 \text { MED } \\
-0,0000\end{array}$ & $-0,2887$ & $-0,5123$ & 0,0614 & $\begin{array}{l}0,0625 \text { MED } \\
-01021 \text { erNac }\end{array}$ \\
\hline $\begin{array}{l}0,3563 \\
0,2857\end{array}$ & $\begin{array}{l}0,6611 \\
0,1514\end{array}$ & $\begin{array}{c}0,5570 \\
0,4331\end{array}$ & $\begin{array}{c}-0,0000 \\
\text { ferNac } \\
-0,3780 \\
\text { FERINTER }\end{array}$ & $\begin{array}{l}0,0000 \\
0,3780\end{array}$ & $\begin{array}{l}0,4344 \\
0,4987\end{array}$ & $\begin{array}{l}-0,1002 \\
-0,1071\end{array}$ & $\begin{array}{l}-0,1021 \text { ferNac } \\
0,0546 \\
\text { FERINTER }\end{array}$ \\
\hline$-0,3563$ & $-0,2479$ & 0,2532 & 0,0000 VNAC & 0,0000 & $-0,1126$ & 0,1002 & $-0,1531$ VNAC \\
\hline 0,1905 & 0,3534 & 0,4331 & $\begin{array}{l}-0,3780 \\
\text { VINTER }\end{array}$ & 0,3780 & 0,3612 & 0,0536 & $\begin{array}{l}-0,0546 \\
\text { VINTER }\end{array}$ \\
\hline 0,2851 & 0,1221 & 0,0623 & 0,1741 CNAC & $-0,1741$ & 0,1347 & $-0,3207$ & 0,2010 CNAC \\
\hline 0,4364 & 0,0578 & $-0,0248$ & $\begin{array}{r}-0,1155 \\
\text { CINTER }\end{array}$ & 0,1155 & 0,1576 & 0,1473 & $\begin{array}{l}0,0000 \\
\text { CINTER }\end{array}$ \\
\hline 0,3751 & 0,4798 & 0,6119 & $\begin{array}{c}-0,2158 \\
\text { CTDATCV }\end{array}$ & 0,2158 & 0,5419 & $-0,1651$ & $\begin{array}{l}0,0561 \\
\text { CTDATCV }\end{array}$ \\
\hline$-0,0891$ & 0,4840 & 0,3798 & $\begin{array}{c}-0,2357 \\
\text { CTDPROIN }\end{array}$ & 0,2357 & 0,1930 & 0,0501 & $\begin{array}{l}-0,1021 \\
\text { CTDPROIN }\end{array}$ \\
\hline
\end{tabular}

DRd - Desenvolvimento Regional em debate (ISSNe 2237-9029) 


\begin{tabular}{|c|c|c|c|c|c|c|c|}
\hline 0,3361 & 0,7045 & 0,3647 & $\begin{array}{c}-0,2425 \\
\text { INNMAY }\end{array}$ & 0,2425 & 0,4304 & $-0,1031$ & $\begin{array}{l}-0,1400 \\
\text { INNMAY }\end{array}$ \\
\hline$-0,2182$ & $-0,4627$ & $-0,4465$ & $\begin{array}{c}0,1155 \\
\text { MFR910 }\end{array}$ & $-0,1155$ & $-0,0788$ & 0,0982 & $\begin{array}{l}0,2500 \\
\text { MER910 }\end{array}$ \\
\hline 0,2857 & 0,7824 & 0,4601 & $-0,1260$ MER 10 & 0,1260 & 0,4128 & 0,0536 & $\begin{array}{l}-0,2182 \\
\text { MER10 }\end{array}$ \\
\hline$-0,7237$ & $-0,4708$ & $-0,4363$ & 0,2901 INTES & $-0,2901$ & $-0,5307$ & 0,0247 & 0,0503 INTES \\
\hline$-0,2182$ & $-0,0193$ & 0,0000 & $\begin{array}{l}-0,1925 \\
\text { INTEN1125 }\end{array}$ & 0,1925 & 0,2102 & $-0,0000$ & $\begin{array}{l}0,1667 \\
\text { INTEN1125 }\end{array}$ \\
\hline \multirow[t]{7}{*}{1,0000} & 0,5300 & 0,3519 & $\begin{array}{c}-0,1260 \\
\text { inten2650 }\end{array}$ & 0,1260 & 0,3268 & $-0,1071$ & $\begin{array}{l}0,0546 \\
\text { inten } 2650\end{array}$ \\
\hline & \multirow[t]{6}{*}{1,0000} & 0,6528 & $\begin{array}{l}-0,3005 \\
\text { PRODEXPO }\end{array}$ & \multirow{6}{*}{$\begin{array}{l}0,5872 \\
-1,0000 \\
1,0000\end{array}$} & 0,6062 & $-0,2413$ & $\begin{array}{l}-0,1157 \\
\text { PRODEXPO }\end{array}$ \\
\hline & & \multirow[t]{5}{*}{1,0000} & $\begin{array}{l}-0,5872 \\
\text { MERCEXPO }\end{array}$ & & 0,6452 & $-0,2192$ & $\begin{array}{l}-0,2171 \\
\text { MERCEXPO }\end{array}$ \\
\hline & & & $\begin{array}{l}1,0000 \\
\text { MENDISTA }\end{array}$ & & $-0,5005$ & 0,1984 & $\begin{array}{l}0,2887 \\
\text { MENDISTA }\end{array}$ \\
\hline & & & & & 0,5005 & $-0,1984$ & $\begin{array}{l}-0,2887 \\
\text { mayorDISTAN } \\
\text { CIA }\end{array}$ \\
\hline & & & & & 1,0000 & $-0,0774$ & $\begin{array}{l}-0,4138 \\
\text { totalinve }\end{array}$ \\
\hline & & & & & & 1,0000 & $\begin{array}{l}-0,2454 \\
\text { PORCSECA } \\
1,0000 \text { INAC }\end{array}$ \\
\hline Pinac & II & PII & EXPLO & & ANALIZ & DEFENS & medtam \\
\hline 0,3711 & $-0,2420$ & 0,2420 & 0,8642 EXP & & $-0,0573$ & $-0,5625$ & $-0,3038$ EXP \\
\hline$-0,2500$ & $-0,1048$ & 0,1048 & $-0,4201$ PEQ & & 0,1048 & 0,2000 & 0,3015 PEQ \\
\hline$-0,0625$ & 0,1048 & $-0,1048$ & -0,8402 MED & & 0,1048 & 0,5000 & 0,5528 MED \\
\hline 0,1021 & $-0,1712$ & 0,1712 & 0,5145 ferNac & & 0,0428 & $-0,4082$ & $-0,0821$ ferNac \\
\hline$-0,0546$ & $-0,2516$ & 0,2516 & $\begin{array}{c}0,3361 \\
\text { FERINTER }\end{array}$ & & $-0,2516$ & $-0,0000$ & $\begin{array}{l}-0,2851 \\
\text { FERINTER }\end{array}$ \\
\hline 0,1531 & 0,3852 & $-0,3852$ & 0,0572 VNAC & & 0,1712 & $-0,2041$ & 0,2872 VNAC \\
\hline 0,0546 & 0,0229 & $-0,0229$ & 0,2750 VINTER & & 0,2516 & $-0,4364$ & $-0,1535$ VINTER \\
\hline$-0,2010$ & $-0,0316$ & 0,0316 & $-0,0985$ CNAC & & $-0,2423$ & 0,3015 & $-0,1919$ CNAC \\
\hline 0,0000 & $-0,1048$ & 0,1048 & 0,1400 CINTER & & $-0,3145$ & 0,2000 & $-0,1005$ CINTER \\
\hline$-0,0561$ & $-0,1019$ & 0,1019 & $\begin{array}{c}0,4500 \\
\text { CTDATCV }\end{array}$ & & $-0,0235$ & $-0,2990$ & $\begin{array}{l}-0,2930 \\
\text { CTDATCV }\end{array}$ \\
\hline 0,1021 & 0,2568 & $-0,2568$ & $\begin{array}{c}0,5145 \\
\text { CTDPROIN }\end{array}$ & & 0,2568 & $-0,6124$ & $\begin{array}{l}-0,2872 \\
\text { CTDPROIN }\end{array}$ \\
\hline 0,1400 & $-0,3083$ & 0,3083 & 0,6078 INNMAY & & $-0,0147$ & $-0,4201$ & $-0,4644$ \\
\hline$-0,2500$ & $-0,3145$ & 0,3145 & $-0,1400$ MER910 & & $-0,3145$ & 0,4000 & $-0,1005$ MER910 \\
\hline 0,2182 & $-0,2516$ & 0,2516 & 0,3361 MER10 & & 0,2059 & $-0,4364$ & $-0,2851$ MER10 \\
\hline$-0,0503$ & 0,4530 & $-0,4530$ & $-0,4644$ INTES & & 0,0316 & 0,3015 & $-0,0101$ INTES \\
\hline$-0,1667$ & $-0,2446$ & 0,2446 & $\begin{array}{c}0,3267 \\
\text { INTEN1125 }\end{array}$ & & $-0,2446$ & $-0,0000$ & $\begin{array}{l}-0,3685 \\
\text { INTEN1125 }\end{array}$ \\
\hline$-0,0546$ & $-0,2516$ & 0,2516 & 0,3361 inten 2650 & & $-0,0229$ & $-0,2182$ & 0,1535 inten 2650 \\
\hline 0,1157 & $-0,2849$ & 0,2849 & $\begin{array}{c}0,6235 \\
\text { PRODEXPO }\end{array}$ & & 0,1394 & $-0,5783$ & $\begin{array}{l}-0,4708 \\
\text { PRODEXPO }\end{array}$ \\
\hline 0,2171 & $-0,0390$ & 0,0390 & $\begin{array}{c}0,3995 \\
\text { MERCEXPO }\end{array}$ & & 0,4551 & $-0,7194$ & $\begin{array}{l}-0,1122 \\
\text { MERCEXPO }\end{array}$ \\
\hline$-0,2887$ & 0,0605 & $-0,0605$ & $\begin{array}{c}-0,2425 \\
\text { MENDISTA }\end{array}$ & & $-0,4237$ & 0,5774 & $\begin{array}{l}0,2901 \\
\text { MENDISTA }\end{array}$ \\
\hline 0,2887 & $-0,0605$ & 0,0605 & $\begin{array}{c}0,2425 \\
\text { mayorDISTANCI } \\
\mathrm{A}\end{array}$ & & 0,4237 & $-0,5774$ & $\begin{array}{l}-0,2901 \\
\text { mayorDISTANCI } \\
\mathrm{A}\end{array}$ \\
\hline 0,4138 & $-0,5701$ & 0,5701 & 0,5408 totalinve & & 0,1735 & $-0,5517$ & $-0,5307$ totalinve \\
\hline 0,2454 & $-0,0257$ & 0,0257 & $\begin{array}{c}-0,0344 \\
\text { PORCSECA }\end{array}$ & & $-0,1801$ & 0,1964 & $\begin{array}{l}0,2713 \\
\text { PORCSECA }\end{array}$ \\
\hline$-1,0000$ & 0,1048 & $-0,1048$ & $-0,1400$ INAC & & $-0,1572$ & 0,2500 & 0,0503 INAC \\
\hline 1,0000 & $-0,1048$ & 0,1048 & 0,1400 pinac & & 0,1572 & $-0,2500$ & $-0,0503$ pinac \\
\hline & 1,0000 & $-1,0000$ & $-0,3083 \mathrm{II}$ & & 0,3407 & $-0,1048$ & $0,4530 \mathrm{II}$ \\
\hline & & 1,0000 & 0,3083 PII & & $-0,3407$ & 0,1048 & $-0,4530$ PII \\
\hline & & & 1,0000 EXPLO & & $-0,3083$ & $-0,4201$ & -0,4644 EXPLO \\
\hline & & & & & 1,0000 & $-0,7338$ & 0,2423 ANALIZ \\
\hline & & & & & & 1,0000 & 0,1005 DEFENS \\
\hline & & & & & & & 1,0000 medtam \\
\hline
\end{tabular}

Observaciones 1 - 20; valor crítico al 5\% (a dos colas $)=0,4438$ para $n=20$ 


\section{RESULTADOS DEL ANÁLISIS DE REGRESIÓN}

Las variables que han sido involucradas en el análisis de regresión y que han resultado estadísticamente significativas, han sido definidas en la Tabla $\mathrm{N}^{\circ} 4$, de la siguiente manera:

a) EXP: Exportaciones en US\$. Variable cuantitativa.

b) FERNAC: Variable cualitativa de tipo binaria, toma valor 1 si la empresa participa en ferias y 0 si no lo hace.

c) INNMAY: Variable cualitativa de tipo binaria, toma valor 1 si la empresa ha realizado una innovación de productos con mayor valor agregado y 0 si no lo hizo.

d) INTENS: porcentaje de ventas destinadas al mercado externo. Es una variable cualitativa tipo binaria que toma valor 1 si ese porcentaje es menos del $10 \%$ y 0 para cualquier otro nivel de porcentaje. De la muestra obtenida, el 55\% de las empresas destina menos del $10 \%$ de su producción al mercado externo.

e) MENDISTA: Variable cualitativa de tipo binaria, toma valor 1 si un $60 \%$ de sus productos son colocados en mercados de América Latina y 0 si los mismos son colocados en otros mercados.

f) INAC: Variable cualitativa de tipo binaria, mide la importancia asignada a las barreras domesticas para exportar toma valor 1 si la empresa le da mucha importancia a las mismas y 0 si le da una importancia menor.

g) PII: Variable cualitativa de tipo binaria, mide la importancia asignada a las barreras internacionales para exportar toma valor 1 si la empresa le asigna poca importancia a las mismas y 0 si le da una importancia mucho mayor.

h) EXPLO: es una variable cualitativa que representa la estrategia de exportación llevada a cabo por la empresa. Es de tipo binaria, tomando valor 1= si la estrategia es de tipo exploradora y 0 para cualquier otro tipo de estrategia.

i) $\mathrm{FACP}=$ variable de tipo cualitativa que mide el tamaño de facturación de las pymes. Toma valor 1 si la empresa es pequeña (factura entre $+1,8$ a 10,3 millones de pesos) y 0 si la empresa es mediana y mediana+ (factura entre $+10,3$ y 82,2 millones de pesos). 
Tabla 4 - Resultados del análisis de regresión

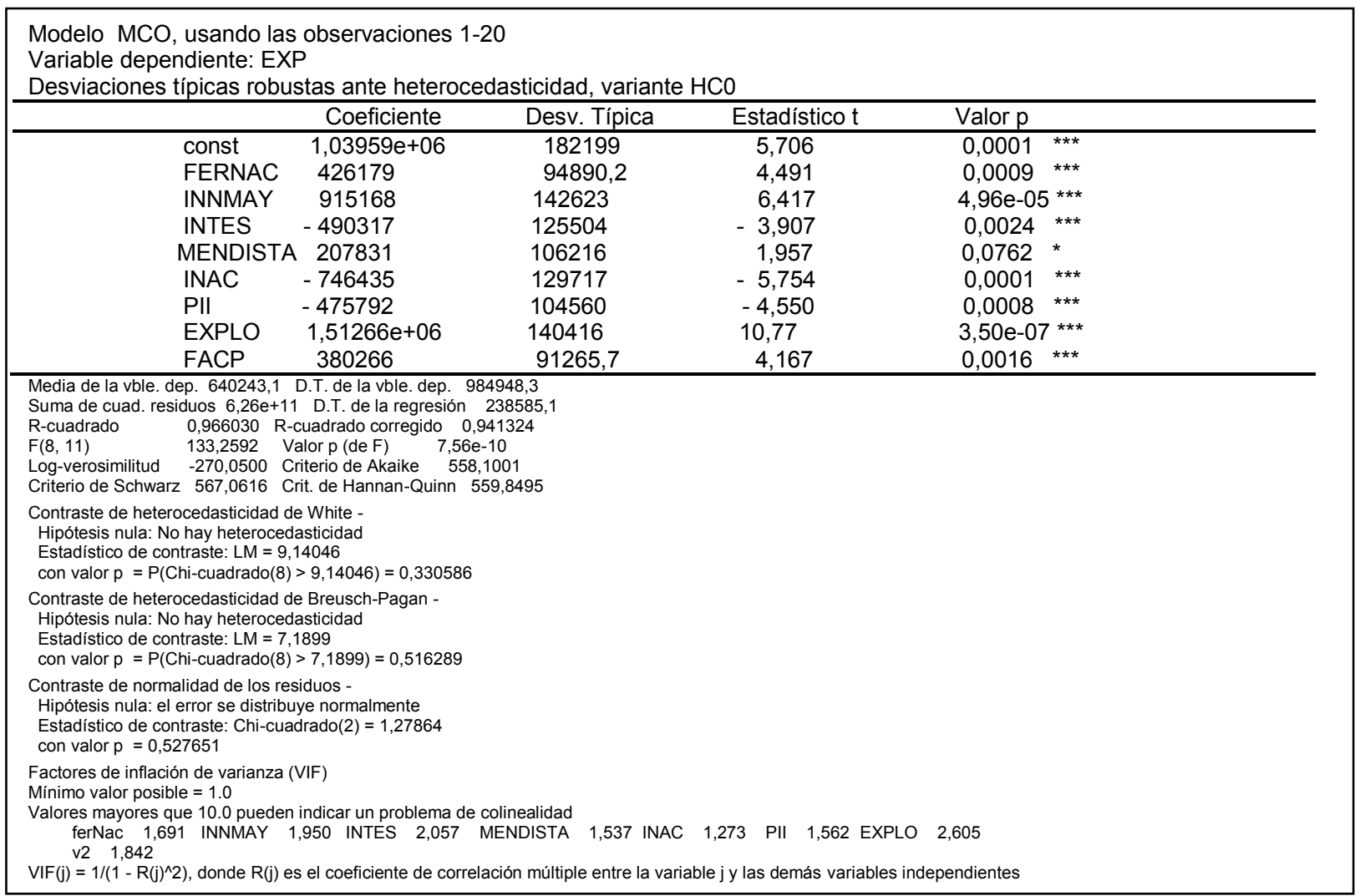

Todas las variables han resultado ser significativas al 95\% de confianza, a excepción de MENDISTA que resultó significativa al 90\%. Se realizó una corrección de White mediante una estimación robusta para eliminar el problema de heterocedasticidad.

Los resultados encontrados son los siguientes:

a) FERNAC: La diferencia en exportaciones entre una empresa que participa en ferias respecto de otra que no lo hace es de US\$ 426.179.

b) INNMAY: Una empresa que realiza una mayor innovación en sus productos exporta US\$ 915.168 más respecto de otra que no ha innovado ni ha agregado valor.

c) INTENS: Una empresa que destina menos del 10\% de sus ventas al mercado externo exporta US\$ 49.0317 menos comparada con una empresa que destina más del $10 \%$ de sus ventas al mercado externo.

d) MENDISTA: Una empresa que coloca sus producto en América Latina (menor distancia) exporta US\$207.831 más que cualquier otra empresa que coloca sus productos en otros mercados.

e) EXPLO: Una empresa exploradora exporta US\$ 1.512.660 más que cualquier otra empresa. 
f) PII: Una empresa que percibe un impacto poco importante de las barreras internacionales, exporta US\$ 475.792 más que una empresa que le otorga una importancia mayor.

g) INAC: Una empresa que percibe un impacto importante de una barrera del mercado nacional, exporta US\$ 746.435 menos que una empresa que le otorga a las barreras locales poca importancia.

h) FACP: Una empresa con facturación pequeña exporta US\$ 380.266 respecto a cualquier otra empresa de distinto tamaño.

Cabe resaltar que algunos signos no son los esperados. Estimamos que pueden surgir por la conformación de la base de datos y el tamaño de la muestra. Las variables que no muestran los signos esperados son las siguientes:

a. MENDISTA: Se esperaría que una empresa que coloca sus productos en A. Latina (menor distancia) exporte valores menores que cualquier otra empresa que coloca sus productos en una mayor proporción de sus ventas en mercados más alejados. Dado que el peso relativo de las PyMes que solo comercializan a estos mercados es del 5,70\% sobre las ventas totales, con valores de exportación menores a la media en el año 2010, y representan el 25\% de las Pymes. Lo que estaría indicando un sesgo en la conformación de la base de datos y del tamaño de la muestra.

b. FACP: Se esperaría que una empresa con facturación pequeña resulte de signo negativo respecto a cualquier otra empresa de mayor tamaño. El resultado de signo positivo podría explicarse debido a que de las 9 empresas que son consideradas pequeñas por su nivel de facturación, 6 son medianas respecto a su capacidad instalada (producen entre $600-1900 \mathrm{~m} 3$ ). Pero, estas 6 empresas exportan el 22\% del total de exportaciones en US\$ de las Pymes analizadas, y solo 2 concentran el $90 \%$ de estas ventas. Lo que indicaría un sesgo del tamaño de la muestra.

\section{DISCUSIÓN}

El análisis de correlación validó las características esenciales de los perfiles estratégicos actualizados de Miles y Snow que representan "[...] patrones subyacentes de respuesta" de las organizaciones a los cambios tecnológicos y de mercado (KETCHEN, 2003, p. 99). Los tipos de estrategias competitivas de las PyMes se pueden identificar por rasgos diferenciadores a partir de las capacidades para mejorar e innovar en los procesos del negocio $\mathrm{y}$ en productos-mercados en el desarrollo de la actividad exportadora.

Las empresas que implementan estrategias exploradoras tienen una relación positiva con mayores resultados, y están vinculadas positivamente con empresas de tamaño medianagrande, de mayor facturación; cantidad de productos exportados; innovación en productos de mayor agregado y precios; inversiones en tecnologías y procesos; desarrollo de productos de mayor transformación y valor agregado; actividades de promoción y vinculación ; intensidad de exportación por encima del 11 al 50\%; experiencia en el mercado más de 10 años; poca 
relevancia a barreras u obstáculos en los mercados nacionales y externos; diversificación en mercados de mayor distancia.

Las defensoras tienen una relación negativa con mayores resultados, y están vinculadas positivamente con: las empresas de tamaño pequeñas y medianas; mercados de destino de menor distancia; experiencia en el mercado menor a 10 años; intensidad de exportación menor de $10 \%$; alta relevancia a obstáculos nacionales; poca relevancia a las barreras en los mercados externos.

Las analizadoras tienen una relación negativa con mayores resultados, y están vinculadas positivamente con: las empresas de tamaño medianas y pequeñas; diversificación en mayor cantidad de mercados; en destinos de mayor distancia; relevancia a las barreras en los mercados externos; experiencia en el mercado de más de 10 años; inversiones en tecnología y procesos; poca relevancia a obstáculos nacionales; diversidad de productos y de mayor transformación y valor agregado; intensidad de exportación menor de de $10 \%$. Si bien las actividades de promoción y vinculación en general tienen una relación negativa, se destaca las asociación positiva con la recepción de visitas a planta industrial de compradores.

Parecería más seguidora de las exploradoras, pero no innovan en productos y percibe un mayor impacto a las barreras en los mercados externos. Actuando a la defensiva en función del entorno, con una intensidad de exportación menor de de $10 \%$, en busca del equilibrio y siguiendo una estrategia más cuidadosas que las exploradoras (ARAGÓN; SÁNCHEZ, 2005; GARCÍA PEREZ DE LEMA; GALLEGO, 2006).

Los resultados de la exportación de las PyMes resultan significativos en su relación con:

a. la innovación en productos de mayor valor agregado y precios, que constituyen un comportamiento de cambio y generan factores diferenciadores de ventajas competitivas para aumentar la productividad de la empresa y competitividad en los mercados externos;

b. la menor o baja percepción empresarial del impacto de las barreras u obstáculos del mercado nacional e internacional, que condicionan el crecimiento de las PyMes ya que impactan sobre su comportamiento estratégico y en la inversión de sus recursos (JIMÉNEZ et al., 2013);

c. la menor intensidad de la exportación (menos del 10\% de sus ventas al mercado externo), por lo que existiría un umbral mínimo de participación de las ventas asociado con el mayor resultado exportador, que según Lages y Montgomery (2004) vinculan con el grado de compromiso alcanzado en los mercados externos, por asignar más recursos a las actividades de exportación en el largo plazo. El 45\% de las Pymes que han alcanzado a superar dicho umbral, entre + de $10 \mathrm{y}$ más de $50 \%$ de las ventas, representan el $88,71 \%$ de las ventas totales; se destaca una participación similar de pequeñas a medianas-grandes empresas, por su nivel de facturación anual.

d. Presencia en ferias comerciales, como instrumento de promoción de las exportaciones, que genera acumulación de conocimientos para responder a las señales del mercado sobre nuevas necesidades y oportunidades de negocios. 
e. Estas dimensiones se reflejan en las estrategias exploradoras, que resultó estadísticamente significativa sobre el resultado exportador, a diferencia de los otros perfiles, como respuesta a su mayor capacidad para adaptarse a las tendencias del entorno.

\section{CONCLUSIÓN}

El estudio analiza las relaciones del comportamiento y estrategias en las PyMes exportadoras de madera de Misiones. y el resultado exportador. Asimismo, se examina la asociación de las tipologías exploradoras, analizadoras y defensoras en el resultado exportador, por lo tanto, se analizaron los efectos directos e indirectos entre las variables de investigación.

La estrategia competitiva en el proceso del desarrollo exportador de las PyMes está asociada con las decisiones empresariales de afectación de recursos para mejorar e innovar en las actividades de la empresa, que condicionan la intensidad de la orientación al mercado externo frente a condiciones del entorno interno y externo.

Las características esenciales revelan que las PyMes exploradoras, con una intensidad de exportación superior al 10\% de las ventas externas, producen cambios e innovación, en el desarrollo de nuevos productos y de mayor valor agregado y precios, innovan en productos con inversión en tecnología y en procesos, y realizan actividades de promoción y vinculación, con destacada participación en ferias nacionales y visitas a planta industrial de compradores internacionales que conducen a mejores oportunidades de negocios.

Las defensoras, a diferencia de las exploradoras, utilizan los mecanismos que le brindan estabilidad, baja intensidad de exportación, menor diversidad de productos y mercados, en destinos cercanos. Y la menor asignación de recursos le facilita la reducción de costos, en innovación, inversión en tecnología y actividades de promoción.

Las analizadoras tienen una baja intensidad de exportación, pero se hace más difuso el límite con las exploradoras, cuando muestran una diversidad de productos de mayor valor agregado, diversificación en mercados distantes con productos de mayor valor agregado, realizan inversiones en tecnología y procesos. Parecería más seguidora de las exploradoras, pero no innovan en productos de mayor valor agregado y en las actividades de promoción y vinculación.

Surge que las exploradores son las PyMes pioneras de nuevos productos o el desarrollo del mercado, y resultó ser más eficaz en entorno cambiante; las defensoras, son las que se dedican a poco o ningún desarrollo del mercado de productos, compitiendo principalmente en función del precio; y las analizadores, recorren un camino intermedio.

Los resultados de la exportación de las PyMes son significativos en su relación con: la innovación en productos de mayor valor agregado y precios, la mayor intensidad de la exportación respecto sus ventas totales, presencia en ferias comerciales y el grado de percepción del impacto de las barreras u obstáculos del mercado nacional e internacional; 
dimensiones estas que se reflejan en los rendimientos de las estrategias exploradoras, como respuesta a su mayor capacidad para adaptarse a las tendencias del entorno, que los analizadores y los defensores.

La percepción en las PyMes de mayores barreras en el mercado nacional, como las defensoras, son condicionantes de una mayor productividad y por ende de la competitividad a nivel internacional, que gravitan en su decisión de inversión de recursos en los mercados externos.

En resumen, el aporte de este trabajo cubre un vacío en la investigación de las exportaciones de la región, mostrando el importante papel de la innovación de productos de mayor valor agregado $\mathrm{y}$ actividades de promoción $\mathrm{y}$ vinculación en las estrategias exploradoras, que aumentarían el desarrollo proactivo de los comportamientos estratégicos, haciendo una contribución positiva a los resultados de exportación.

Este estudio tiene la limitación asociada con el tamaño de la muestra, a pesar que se encontraron varios resultados importantes, en posteriores trabajos se podría ampliar la muestra para un análisis más robusto de los datos estadísticos. Asimismo, no incluye las PyMes como proveedoras de empresas que exportan o de una cadena de valor que destina parte de su producción al mercado externo. Lo cual, futuras investigaciones podrían contribuir al mejoramiento de sus capacidades competitivas y su inclusión en la oferta exportable provincial.

La mayor presencia de estrategias defensoras en las PyMes plantearía estudiar los motivos de las decisiones estratégicas, que podrían dar luz en aquellas dimensiones que habría que fortalecer en el apoyo de este segmento empresarial con experiencia exportadora.

\title{
REFERENCIAS
}

ALONSO RODRÍGUEZ, J.A.; DONOSO DONOSO, V. Modelización del comportamiento de la empresa exportadora española. Revista ICE, v. 788, p. 35-58, 2000.

\author{
ALONSO, J. A.; DONOSO, V. Competir en el exterior. La empresa española y los \\ mercados internacionales. Madrid: Instituto Español de Comercio Exterior, 1998. 434 p.
}

ARAGÓN SÁNCHEZ, A.; SÁNCHEZ-MARÍN, G. Strategic orientation, management characteristics, and performance: a study of Spanish SMEs. Journal of Small Business Management , v. 43, n. 3, p. 287-308, 2005.

ARGENTINA. Subsecretaría de Desarrollo Forestal de Misiones, Facultad de Ciencias Forestales-UNaM. Sistema de Información Foresto-Industrial Provincial-SIFIP. Censo de la Industria de la Madera de Misiones 2010. Disponible en: <http://facfor.unam.edu.ar/sifip> Acceso el 26 nov. 2012. 
ARGENTINA. Ministerio de Industria. Secretaría de la Pequeña y Mediana Empresa y Desarrollo Regional-SEPYME. Micro, Pequeñas y Medianas empresas, determinación del valor de las ventas anuales, Resolución 21/2010. 10 de Agosto de 2010. Disponible en: $<$ http://infoleg.mecon.gov.ar> Acceso el 26 nov. 2012.

CABELLO MEDINA, C. et al. Tipología estratégica de Miles y Snow y factores competitivos: Un análisis empírico. Cuadernos de Economía y Dirección de la Empresa, n.7, p. 365-382, 2000.

CARNEIRO, J.; DA ROCHA, A.; DA SILVA, J. F. Determinants of Export Performance: a Study of Large Brazilian Manufacturing Firms. Brazilian Administration Review, Curitiba, v. 8 , n. 2, art. 1, p. 107-132, 2011

CAVUSGIL, S. T.; ZOU, S. 1994. Marketing strategy-performance relationship: An investigation of the empirical link in export market ventures. The Journal of Marketing, $v$. 58, n.1, p.1-21, 1994.

ESCANDÓN D.; HURTADO AYALA A. Y CASTILLO CAICEDO M. Influencia de las barreras a la exportación sobre el compromiso exportador y su incidencia en los resultados internacionales. Revista Escuela Administración de Negocios, n. 75, p. 38-55, 2013.

FLOR PERIS, M. L.; OLTRA MESTRE M.J. La estrategia exportadora de la empresa y su relación con el resultado Internacional. Academia Europea de Dirección y Economía de la Empresa, v. 16, n. 1, p. 15-29, 2010.

FRISHAMMAR, J. Organizational environment revisited. International Studies of Management \& Organization, v. 36, n. 3, p. 22-49, 2006.

GARCÍA PÉREZ DE LEMA, D.; MARTÍNEZ GARCÍA, D.; ARAGÓN SÁNCHEZ, A. Análisis Estratégico para el Desarrollo de la MPYME en Iberoamérica. Colombia: Editorial Universidad Politécnica de Cartagena, 2009. 146 p.

GARCÍA PEREZ DE LEMA, D.; GALLEGO MERINO, A, M. Influencia de la Estrategia en el crecimiento y rentabilidad de la PyMe industrial española. Revista Española de Financiación y Contabilidad, v. XXXV, n. 129, p. 437-455, 2006.

GARCIA, F.; AVELLA, L. Intensidad exportadora y percepción de barreras a la exportación: un estudio de casos. Investigaciones Europeas de Dirección y Economía de la Empresa, v. 13, n.3, p. 93-106, 2007.

GIMENEZ, F. Estratégia em Pequenas Empresas: uma Aplicação do Modelo de Miles e Snow. Revista de Administração Contemporânea, v. 3, n. 2, p. 53-74, 1999.

GUARROCHENA, M. et al. Dinámica del proceso de desarrollo exportador de PyMes madereras de Misiones. Misiones, Argentina, Investigación Código 16/ E146, Facultad de Ciencias Económicas- UNaM, 2013. 
GUARROCHENA, M. Las Barreras Comerciales en el sector forestal: Impacto en pequeñas y medianas empresas industriales madereras de Misiones, Argentina, Tesis (Maestría en Integración Económica Global y Regional) - Universidad Internacional de Andalucía, España, 2011.

HITT, M.A.; HOSKISSON, R.E.; KIM, H. International diversification: Effects on innovation and firm performance in product-diversified firms. Academy of Management Journal, v. 40, n. 4, p. 767-799, 1997.

JIMENEZ CASTILLO, D. et al. Análisis de los efectos moderadores de la inversión en I+D y la experiencia exportadora sobre la relación entre barreras a la exportación e intensidad exportadora bajo distintos niveles de turbulencia ambiental percibida. Cuadernos de Economía y Dirección de la Empresa, v.16, n. 2, p. 95-107, 2013.

JULIAN, C., Y AHMED, Z. The impact of Barriers to Export on Export Marketing Performance. Journal of Global Marketing, v. 19, n. 1, p. 71-94, 2005.

KETCHEN Jr., D. J. An interview with Raymond E. Miles and Charles C. Snow. Academy of Management Executive, v. 17, n. 4, p. 97-104, 2003.

KATSIKEAS, C.S.; LEONIDOU, L.C.; MORGAN, N.A. Firm-level export performance assessment: Review, evaluation, and development. Journal of the Academy of Marketing Science, Vol. 28, nº 4, pp. 493-511, 2000.

LAGES, L. F.; SOUSA, C. M.P. Export Performance. In: BELLO, D. C.; GRIFFITH, D. A. (Volume Editors). Wiley International Encyclopedia of Marketing: International Marketing.6, USA: Wiley and Sons Ltd., 2010.

LAGES, L. F.; SILVA, G.; STYLES, C. Relationship Capabilities, Quality, and Innovation as Determinants of Export Performance. Journal of International Marketing, v. 17, n. 4, p. 47-70, 2009.

LAGES, L.F.; MONTGOMERY, D.B. Export performance as an antecedent of export commitment and marketing strategy adaptation. Evidence from small and medium-sized exporters. European Journal of Marketing, v. 38, n. 9/10, p.1186-1214, 2004.

LAHURA, E. El Coeficiente de correlación y correlaciones espúreas. Pontificia Universidad Católica del Perú, Departamento de Economía, Documento de Trabajo, n. 218, 2003.

LEONIDOU, L. C. Analysis of the barriers hindering small business export development. Journal of Small Business Management, v. 42, n. 3, p. 279-302, 2004.

LEONIDOU, L.; KATSIKEAS C. SAMIE, S. Marketing Strategy Determinants of Export Performance: A Meta-Analysis. Journal of Business Research, v.55, n.1 p.51-67, 2002.

LOZANO POSSO, M. Factores de reciente énfasis en la relación diversificación-resultados. Estudios Gerenciales, v. 20, n. 90, p. 35-56, 2004.

MILES, R. E. et al. Organizational Strategy, Structure and Process. The Academy of Management Review, v. 3, n. 3, p. 546-562, jul 1978, Reprinted JSTOR, 2003. 
MILESI, D.; AGGIO, C. Éxito exportador, innovación e impacto social. Un estudio exploratorio de PYMES exportadoras latinoamericanas. Banco Interamericano de Desarrollo. Working paper, Junio 2008, p. 1-159.

MILESI, D.; YOGUEL,G.; MOORI KOENIG, V. Desarrollo de competencias endógenas y éxito exportador en las PyMEs argentinas. En: YOGUEL, G. (editor). Conocimiento y competitividad: Tramas productivas y comercio exterior. Buenos Aires: Editora UNGS, p. 53-107, 2002.

NAVARRO, A. et al. Implications of perceived competitive advantages, adaptation of marketing tactics and export commitment on export performance. Journal of World Business , v. 45, n. 1, p. 49-58, 2010.

RAYMOND, L.; BERGERON, F. Enabling the business strategy of SMEs through ebusiness capabilities: A strategic alignment perspective Industrial. Management \& Data Systems, v. 108, n. 5, p. 577-595, 2008.

ROBERT, V. Prácticas empresariales y éxito exportador de las PYMES en Argentina, Chile y Colombia. En: MILESI, D.; MOORI, V.; YOGUEL, G. (Coord.) El éxito exportador de las PYMES de Argentina, Chile y Colombia. Bolivia: FUNDES, p. 109-200, 2007.

SHOHAM, A. Bounded rationality, planning, standardization of international strategy, and export performance: a structural model examination. Journal of International Marketing, v. 7, n. 2, p. 24-50, 1999.

SOUSA, C. M. Export performance measurement: an evaluation of the empirical research in the literature. Academy of Marketing Science Review, v. 9, n. 12, p. 1-22, 2004.

STOIAN, M.C.; RIALP, A.; RIALP, J. Export performance under the microscope: A glance through Spanish lenses. International Business Review, v. 20, n. 2, 117-135, 2011.

SUÁREZ-ORTEGA S. M.; ÁLAMO-VERA F. R. SMEs’ Internationalization: Firms and Managerial Factors. International Journal of Entrepreneurial Behavior \& Research, v. 11, n. 4 , p. $258-279,2005$.

Artigo recebido em: 10/10/2014

Artigo aprovado em: 08/03/2015 